\title{
Impact of selected magnetic fields on the therapeutic effect in patients with lumbar discopathy: A prospective, randomized, single-blinded, and placebo-controlled clinical trial
}

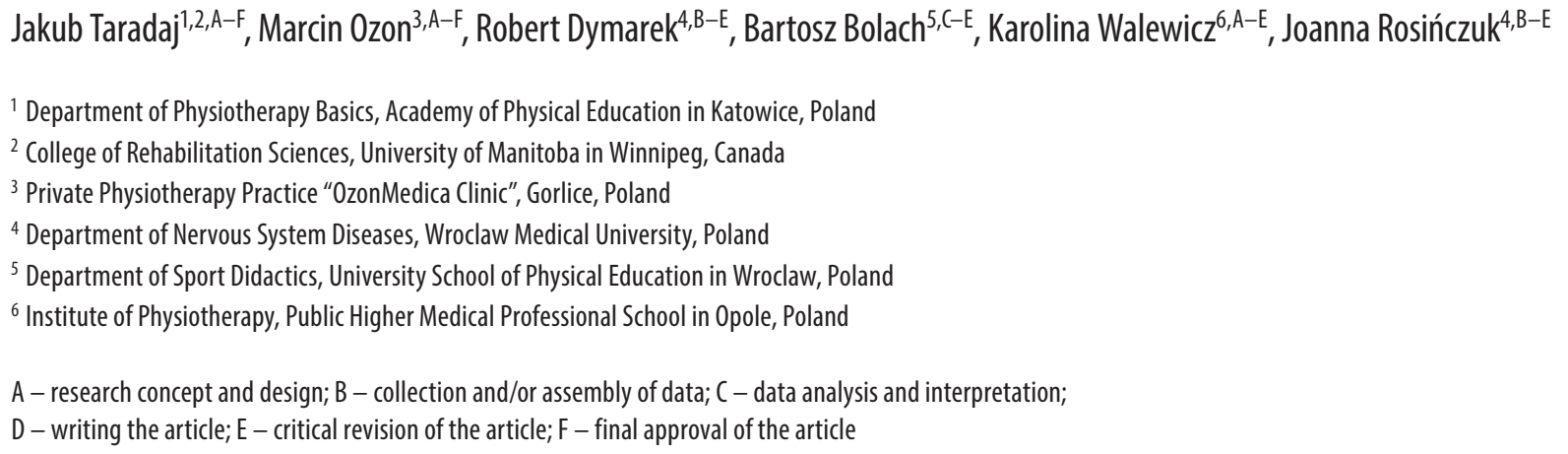

Address for correspondence

Robert Dymarek

E-mail:r.dymarek@gmail.com

Funding sources

None declared

Conflict of interest

None declared

Received on November 16, 2016 Reviewed on November 29, 2016 Accepted on January 27, 2017

\begin{abstract}
Background. Interdisciplinary physical therapy together with pharmacological treatment constitute conservative treatment strategies related to low back pain (LBP). There is still a lack of high quality studies aimed at an objective evaluation of physiotherapeutic procedures according to their effectiveness in LBP.

Objectives. The aim of this study is to carry out a prospective, randomized, single-blinded, and placebocontrolled clinical trial to evaluate the effectiveness of magnetic fields in discopathy-related LBP.
\end{abstract}

Material and methods. A group of 177 patients was assessed for eligibility based on inclusion and exclusion criteria. In the end, 106 patients were randomly assigned into 5 comparative groups: A ( $n=23$; magnetic therapy: $10 \mathrm{mT}, 50 \mathrm{~Hz}) ; \mathrm{B}(\mathrm{n}=23$; magnetic therapy: $5 \mathrm{mT}, 50 \mathrm{~Hz}) ; \mathrm{C}(\mathrm{n}=20$; placebo magnetic therapy); $D$ ( $n=20$; magnetic stimulation: $49.2 \mu \mathrm{T}, 195 \mathrm{~Hz}) ;$ and $\mathrm{E}(\mathrm{n}=20$; placebo magnetic stimulation). All patients were assessed using tests for pain intensity, degree of disability and range of motion. Also, postural stability was assessed using a stabilographic platform.

Results. In this study, positive changes in all clinical outcomes were demonstrated in group A ( $p<0.05)$. The most effective clinical effect was observed for pain reduction $(p<0.05)$, improvement of the range of motion $(p<0.05)$ and functional ability of the spine $(p<0.05)$. It is also worth noting that the effects in the majority of the measured indicators were mostly short-term ( $p>0.05)$.

Conclusions. It was determined that the application of magnetic therapy $(10 \mathrm{mT}, 50 \mathrm{~Hz}, 20 \mathrm{~min})$ significantly reduces pain symptoms and leads to an improvement of functional ability in patients with LBP.

Key words: low back pain, linical assessment, lumbar discopathy, stabilometric platform, magnetic field therapy

DOI

$10.17219 /$ acem $/ 68690$

Copyright

Copyright by Author(s)

This is an article distributed under the terms of the

Creative Commons Attribution Non-Commercial License

(http://creativecommons.org/licenses/by-nc-nd/4.0/) 


\section{Introduction}

Lumbar spinal pain syndrome (LSP), commonly referred to as low back pain (LBP), is defined as pain located between the $12^{\text {th }}$ rib and the inferior gluteal folds, which progresses down the lower extremities with the possibility of peripheralization. ${ }^{1}$ LBP affects a majority of the population, irrespective of age, as it often begins in childhood and adolescence, where the frequency of occurrence is similar to that in the adult population. ${ }^{2}$

LBP occurs at least once in a lifetime in $65-80 \%$ of adults, and in $15 \%$ of patients it occurs more frequently, becoming a chronic condition. ${ }^{3}$ In $54-90 \%$ of patients, symptoms recur within 1 year from the first episode. ${ }^{4,5}$ The chronic form of LBP is a major cause of reduced daily life mobility and activity and the related deteriorated quality of life in persons under the age of 45 years. ${ }^{6,7}$ Despite the seriousness of the problem, it is possible that no more than $10 \%$ of all patients suffering from LBP will seek the help of a physician or a physical therapist. ${ }^{8}$

The lumbar region of the spine is the area where pain is most frequently located due to the greatest multiplane mobility and the occurrence of forces burdening its stabilizing structures, as well as the constant accumulation of micro-injuries and overloading, which most often result from non-ergonomic habits and movement patterns. ${ }^{9,10}$ In the vast majority, i.e., $90 \%$ of all cases, lumbosacral pain is nonspecific and depends on the level of physical activity, among other things, which translates into excessive overload of the spine. . $^{8,11}$

Among the most frequently indicated causes of LBP are degenerative proliferative changes, ankylosing spondylitis, osteoporotic changes, or secondary post-traumatic deformations. However, the most frequent cause of LBP is definitely a chronic intervertebral disc disorder, falling under the term "discopathy". ${ }^{12}$ Long-term persistent changes in the affected spinal segments may provoke chronic structural and degenerative disorders in the muscles of the lumbar region. ${ }^{13}$

In addition to pharmacological treatment, interdisciplinary physical therapy is the superior conservative treatment method for ailments related to LBP. ${ }^{14-17}$ The methods used for therapeutic purposes include standard kinesiotherapeutic exercises, various massage and neuromobilization methods, proprioception training, and manual mobilization and manipulation techniques in individual therapy with the patient, as well as a wide range of physical methods, including magnetic therapy and magnetic stimulation. ${ }^{18-22}$

Even though many various physical therapy methods are used on a daily basis to combat LBP, few of them are based on substantiated and reliable scientific grounds supported by reliable clinical research of high methodological quality. This also refers to the use of magnetic fields, which may often prove to be of little or no help, and are therefore completely pointless.
Undeniably, there is a justified need for the continuous search for the most efficient methods to help an LBP patient in combating the severe and progressive reduction of mobility which results in secondary pathological changes in the form of various asymmetries and destabilization of the postural pattern, as compared to healthy individuals. ${ }^{23,24}$

Observing the center of pressure and asymmetry in the burden placed on feet in patients with LBP using objective tools, such as a stabilometric (posturographic) test, may be a precise method of monitoring the patient's condition and the ongoing progress of therapy. It also offers full control over the complex treatment process and allows the verification of scientific hypotheses during clinical studies. ${ }^{25,26}$

It is worth noting that none of the articles published to date which present the possibilities of therapeutic application of pulsed magnetic fields in LBP have used several comparison groups in 1 experiment (analysis of the potential effect of magnetic induction on clinical effects). Also, no detailed randomization was used, and such studies were often conducted with relatively small groups of patients and were based solely on subjective questionnaires and pain assessment scales, disregarding the available measurement methods which would objectify therapeutic progress. It must also be stressed that the available studies did not include an analysis of long-term follow-up results which would clearly state whether the achieved therapeutic effect was only temporary or whether there was a long-term remission of symptoms.

The purpose of this study was to attempt to carry out a prospective, randomized and controlled clinical trial with a single blind trial and a thorough analysis of the effectiveness of magnetic fields with varying intensity in the treatment of symptoms of discopathy-related LBP, based on reliable and homogeneous research material. The primary goal was to demonstrate the therapeutic efficacy of magnetic fields with different levels of magnetic induction on pain reduction, functional ability improvement, increased range of joint mobility, and a presentation of positive therapeutic effects in terms of postural control. The secondary goal was to identify the most efficient form of magnetic stimulation, considering the values of magnetic induction with regard to the evaluated clinical symptoms and stabilometric parameters.

\section{Material and methods}

\section{Patient qualification}

The research project was approved by the Bioethics Commission of the Academy of Physical Education in Katowice (Poland) with resolution No. 10/2012 of December 13, 2012. The study recruited patients with lumbosacral discopathy, referred for physical therapy to the OzonMedica Clinic in Gorlice (Poland). The project spanned from September 2, 2013 to May 20, 2016. 
The qualification of patients was done by a team composed of an orthopedist, a neurologist, a neurosurgeon, an internist, a radiologist, and a physical therapist. The selection of patients for participation in the study was purposeful. Patients who qualified for the study suffered from L5-S1 discopathy, chronic (lasting over 6 months) radiating pain and pseudoradicular syndrome, and had no previous surgical procedures within the spinal area. The patients had to be at least 18 years old and have recent magnetic resonance imaging (MRI) scans confirming their diagnosis (at least type $\mathrm{III}^{\circ}$ changes in accordance with the Modic classification in the L5-S1 section). The qualified patients were randomly assigned to 6 comparison groups.

\section{Inclusion and exclusion criteria}

Exclusion criteria included: acute spinal pain (lasting less than 6 months, as symptoms lasting longer were treated as chronic), radicular syndrome, discopathy of other spine sections (patients with early type $\mathrm{I}$ and $\mathrm{II}^{\circ}$ changes were not excluded from the study, only type III $^{\circ}$ degeneration as per the Modic classification in the MRI image was grounds for exclusion), no pain or reduction of mobility in the lumbosacral section, other disorders of the spine (spondylolisthesis, fractures, tumors, rheumatic diseases, or cauda equina syndrome), pregnancy, pacemakers, symptoms of defects, cardiovascular diseases, metal implants such as an endoprosthesis of the hip and/or knee joint, mental disorders, cancers, psoriasis, scleroderma, and viral or bacterial infections.

Patients who had undergone spinal surgery or were taking painkillers or anti-inflammatory drugs were also excluded from the study. Moreover, the exclusion criteria included damage to the vestibule and/or a part of the vestibulocochlear nerve, Ménière's syndrome, sudden loss of function of the inner ear, and damage to the cerebellum, spinal cord, or brainstem, resulting in balance disorders.

\section{Patient randomization}

The study was conducted on the intention-to-treat approach (patients who for various reasons did not qualify for subsequent stages of the research project were provided with basic medical treatment - painkillers, non-steroidal anti-inflammatory drugs, and mobility rehabilitation - per medical recommendations). The randomized assignment of patients to individual groups was continuous during the entire duration of the study, i.e., each newly qualified person was randomized by a computer number generator and assigned to a given comparison group accordingly.

\section{Characteristics of the procedures}

Patients in group A were treated with magnetic therapy. The treatment parameters were rectangular flow, a magnetic induction of $10 \mathrm{mT}$, a frequency of $50 \mathrm{~Hz}$, each treatment lasting $20 \mathrm{~min}$, and the application method was an induction coil $60 \mathrm{~cm}$ in diameter.

Patients in group B were also treated with magnetic therapy. The treatment parameters were rectangular flow, a magnetic induction of $5 \mathrm{mT}$, a frequency of $50 \mathrm{~Hz}$, each treatment lasting $20 \mathrm{~min}$, and the application method was an induction coil $60 \mathrm{~cm}$ in diameter.

Patients in group $\mathrm{C}$, however, were treated with pseudomagnetic therapy (simulated treatment: treatment parameters were set with the device switched on, but no real application took place). This group was meant to constitute the single blind trial (patients had no knowledge of which group they belonged to) and to evaluate the placebo effect during studies of this kind of therapy.

Patients in group D were treated with magnetic stimulation. The treatment parameters were rectangular flow, a magnetic induction of $49.2 \mu \mathrm{T}$, a frequency of $195 \mathrm{~Hz}$, each treatment lasting $20 \mathrm{~min}$, and the application method was a pillow $45 \mathrm{~cm} \times 24 \mathrm{~cm} \times 3 \mathrm{~cm}$.

Patients in group E were administered pseudo-magnetic stimulation (treatment parameters were set, but as with group $\mathrm{C}$ no application took place). In this case, the group constituted the blind trial and simulated treatment for real magnetic stimulation.

A detailed flow of participants at each stage of the project is shown in Fig. 1. Patients in all of the comparison groups were homogeneous in terms of basic characteristics specific for the studied populations (Table 1). The groups were also homogeneous as regards the initial measurements concerning pain assessment, functional state, mobility range, and body posture.

Apart from physical therapy, patients in all groups underwent a uniform basic therapy through motor improvement in the form of functional training (45 min once a day for 5 days/ week). Standard stabilization training comprised the following elements: (1) myofascial release techniques for the erector spinae muscle; (2) activation techniques for the neutral position of the lumbo-pelvic-hip complex and deep-core muscles; (3) activation of proper breathing and exercising the transversus abdominis muscle; (4) coordination of the work of superficial and deep-core muscles; and (5) postural and dynamic training.

Patients in all comparison groups were subjected to a series of 15 physical therapy treatments, 5 times a week (Monday to Friday) for a period of 3 weeks. Magnetic therapy (in groups A, B and C) was performed using the Cyborg Mag generator (Cosmogamma, Cento, Italy). Treatments were performed in a coil applicator with a diameter of $60 \mathrm{~cm}$, mounted on the system of longitudinal drive rails of the treatment bed. During treatment, the patients lay down on their back on the treatment bed, and their lumbosacral region was positioned within the induction coil. Magnetic stimulation was performed using the Viofor JPS device (Med \& Life, Komorów, Poland). Treatments were also performed in the lie-back position: the patients lay on the bed so that the lumbosacral section of their spine was directly on a special pillow (applicator), remaining in constant contact. 
Table 1. Characteristics of study population in each group after random allocation

\begin{tabular}{|c|c|c|c|c|c|c|}
\hline Characteristic & Group A & Group B & Group C & Group D & Group E & $p$-value \\
\hline $\begin{array}{l}\text { Gender }(n) \\
\text { female/male }\end{array}$ & $15 / 8$ & $16 / 7$ & $12 / 8$ & $13 / 7$ & $14 / 6$ & $>0.05^{*}$ \\
\hline $\begin{array}{l}\text { Age [years] } \\
\text { mean } \\
\text { SD }\end{array}$ & $\begin{array}{c}50.45 \\
10.11\end{array}$ & $\begin{array}{l}55.20 \\
11.40\end{array}$ & $\begin{array}{c}52.30 \\
8.22\end{array}$ & $\begin{array}{l}51.80 \\
11.50\end{array}$ & $\begin{array}{c}55.75 \\
9.28\end{array}$ & $>0.05^{* *}$ \\
\hline $\begin{array}{l}\text { Hight }[\mathrm{cm}] \\
\text { mean } \\
\text { SD }\end{array}$ & $\begin{array}{c}163.89 \\
5.33\end{array}$ & $\begin{array}{c}168.20 \\
7.18\end{array}$ & $\begin{array}{c}167.10 \\
6.88\end{array}$ & $\begin{array}{c}165.30 \\
6.82\end{array}$ & $\begin{array}{c}164.95 \\
7.66\end{array}$ & $>0.05^{* *}$ \\
\hline $\begin{array}{l}\text { Body mass }[\mathrm{kg}] \\
\text { mean } \\
\text { SD }\end{array}$ & $\begin{array}{l}78.30 \\
17.92\end{array}$ & $\begin{array}{l}72.77 \\
13.10\end{array}$ & $\begin{array}{l}74.77 \\
14.09\end{array}$ & $\begin{array}{l}72.20 \\
12.46\end{array}$ & $\begin{array}{l}79.11 \\
18.11\end{array}$ & $>0.05^{* *}$ \\
\hline $\begin{array}{l}\text { Obesity (n) } \\
\text { BMI > } 30 \mathrm{~kg} / \mathrm{m}^{2}\end{array}$ & 11 & 8 & 6 & 6 & 8 & $>0.05^{*}$ \\
\hline $\begin{array}{l}\text { Disease duration [years] } \\
\text { mean } \\
\text { SD }\end{array}$ & $\begin{array}{l}4.12 \\
3.76\end{array}$ & $\begin{array}{l}3.96 \\
3.12\end{array}$ & $\begin{array}{l}4.35 \\
3.78\end{array}$ & $\begin{array}{l}4.77 \\
4.08\end{array}$ & $\begin{array}{l}4.34 \\
3.89\end{array}$ & $>0.05^{* *}$ \\
\hline $\begin{array}{l}\text { Osteoarthritis (n) } \\
\text { right side/left side }\end{array}$ & $15 / 8$ & $14 / 9$ & $12 / 8$ & $11 / 9$ & $12 / 8$ & $>0.05^{*}$ \\
\hline $\begin{array}{l}\text { Radiological changes in Modic classification (n) } \\
\|^{\circ} / \mathbb{V}^{\circ}\end{array}$ & $17 / 6$ & $16 / 7$ & $15 / 5$ & $15 / 5$ & $14 / 6$ & $>0.05^{*}$ \\
\hline $\begin{array}{l}\text { Pain intensity in VAS (score) } \\
\text { mean } \\
\text { SD }\end{array}$ & $\begin{array}{l}5.80 \\
2.56\end{array}$ & $\begin{array}{l}5.55 \\
1.75\end{array}$ & $\begin{array}{l}5.70 \\
1.88\end{array}$ & $\begin{array}{l}5.70 \\
2.49\end{array}$ & $\begin{array}{l}5.40 \\
1.63\end{array}$ & $>0.05^{* *}$ \\
\hline $\begin{array}{l}\text { Pain intensity in LPS (score) } \\
\text { mean } \\
\text { SD }\end{array}$ & $\begin{array}{l}5.90 \\
2.21\end{array}$ & $\begin{array}{l}6.10 \\
1.89\end{array}$ & $\begin{array}{l}6.30 \\
3.07\end{array}$ & $\begin{array}{l}5.85 \\
2.36\end{array}$ & $\begin{array}{l}6.20 \\
2.83\end{array}$ & $>0.05^{* *}$ \\
\hline $\begin{array}{l}\text { Disability level in ODI (score) } \\
\text { mean } \\
\text { SD }\end{array}$ & $\begin{array}{l}16.50 \\
8.27\end{array}$ & $\begin{array}{l}15.95 \\
8.12\end{array}$ & $\begin{array}{l}16.15 \\
7.98\end{array}$ & $\begin{array}{l}15.70 \\
8.41\end{array}$ & $\begin{array}{l}16.10 \\
8.04\end{array}$ & $>0.05^{* *}$ \\
\hline $\begin{array}{l}\text { Disability level in RMDQ (score) } \\
\text { mean } \\
\text { SD }\end{array}$ & $\begin{array}{c}12.05 \\
6.18\end{array}$ & $\begin{array}{l}13.90 \\
7.12\end{array}$ & $\begin{array}{l}13.10 \\
6.65\end{array}$ & $\begin{array}{l}12.95 \\
6.56\end{array}$ & $\begin{array}{c}13.86 \\
2.16\end{array}$ & $>0.05^{* *}$ \\
\hline $\begin{array}{l}\text { Body posture in sagittal plane }[\mathrm{mm}] \\
\text { mean } \\
\text { SD }\end{array}$ & $\begin{array}{c}125.12 \\
90.11\end{array}$ & $\begin{array}{l}125.19 \\
98.45\end{array}$ & $\begin{array}{l}120.89 \\
104.12\end{array}$ & $\begin{array}{r}123.17 \\
91.22\end{array}$ & $\begin{array}{c}124.03 \\
93.82\end{array}$ & $>0.05^{* *}$ \\
\hline $\begin{array}{l}\text { Body posture in frontal plane }[\mathrm{mm}] \\
\text { mean } \\
\text { SD }\end{array}$ & $\begin{array}{l}101.49 \\
80.23\end{array}$ & $\begin{array}{c}100.21 \\
82.39\end{array}$ & $\begin{array}{c}102.88 \\
85.02\end{array}$ & $\begin{array}{c}102.63 \\
84.12\end{array}$ & $\begin{array}{c}100.95 \\
80.99\end{array}$ & $>0.05^{* *}$ \\
\hline
\end{tabular}

Statistical tests for homogeneity analyses between study groups: ${ }^{*} X^{2}$ test with the highest reliability; ${ }^{*}$ Friedmann's ANOVA homogeneity test; VAS - Visual Analogue Scale; LPS - Laitinen Pain Scale; ODI - Oswestry Disability Index; RMDQ - Roland-Morris Disability Questionnaire.

\section{Pain questionnaires and functional tests}

In order to analyze the therapeutic progress for the subjective assessment of pain, functional capacity and degree of disability, the following tests were performed:

- the Visual Analogue Scale pain assessment scale (VAS) used to subjectively assess the experienced pain. The patient assesses the experienced pain on a simple scale from 0 to 10 , where 0 denotes a lack of pain and 10 denotes the most acute pain;

- the Laitinen Pain Scale (LPS) - in the modified Laitinen Pain Scale, 4 indicators are assessed: pain intensity, frequency of pain occurrence, use of analgesics, and limitations of mobility;

- the Oswestry Questionnaire (The Oswestry LowBack Pain Disability Questionnaire, Oswestry Disability
Index - ODI) - used to evaluate the functional ability of patients; a widely recognized and reliable scale for evaluating patients with low back pain. The questionnaire consists of 10 questions regarding symptoms and everyday activities. When answering the individual questions, the patient can choose 1 of the 6 options scored $0-5$ : $\mathrm{A}-0$ points; $\mathrm{B}-1$ point; $\mathrm{C}-2$ points; $\mathrm{D}-3$ points; $\mathrm{E}-4$ points; and $\mathrm{F}-5$ points. After summing the scores for all questions, the Oswestry Disability Index is calculated as follows: no disability (0-4 points); minimal disability (5-14 points); moderate disability (15-24 points); severe disability (25-34 points); or full disability (35-50 points); - The Roland-Morris Disability Questionnaire(RMDQ) used to assess the degree of disability in patients with low back pain. It reflects the condition of the patient on the day of the examination. The questionnaire contains 


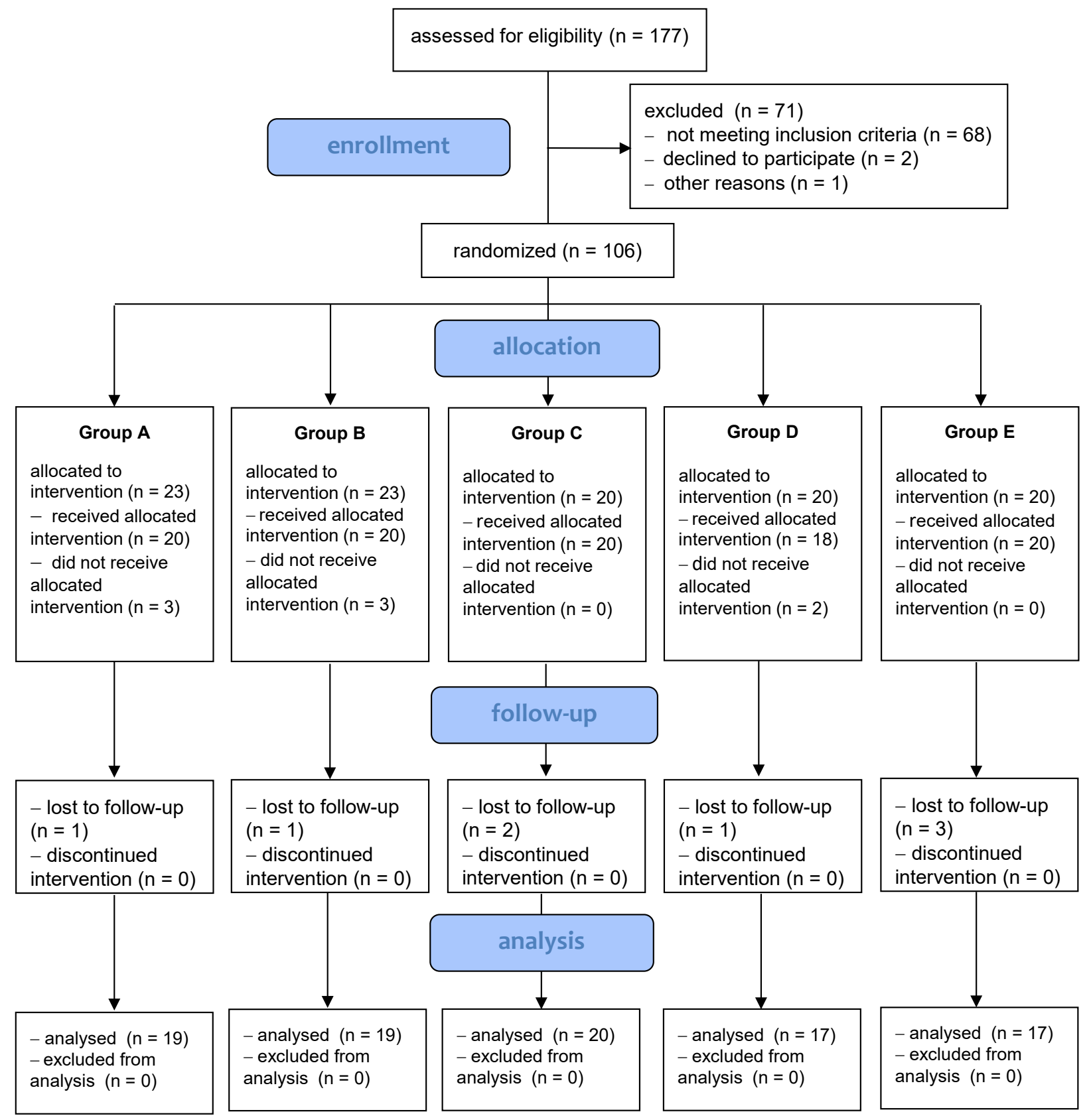

Fig. 1. Flowchart of patients' assessment for eligibility in the study in all stages

24 questions which are answered 'yes' or 'no'. Each 'yes' answer scores 1 point and each 'no' answer scores 0 points. After summing the scores for all questions, the Roland-Morris disability index is given as follows: no disability ( $0-3$ points); minimal disability (4-10 points); moderate disability (11-17 points); or severe disability (18-24 points);

- the Lasègue test ( $\mathrm{LaT})$ - may be used to measure the range of motion of the hip joint on the side of the herniated disc in the course of spinal discopathy. The starting position is with the patient lying down on his or her back with both legs straight. The examiner then slowly lifts one of the patient's legs while the knee is straight at the joint until pain is noted. The mobility range is measured in degrees of angle using a goniometer;

- the Schober test (ShT) - used to evaluate the mobility of the lumbosacral spine. While the patient is in a standing position, the examiner marks 2 points on the patient's skin: the first one $10 \mathrm{~cm}$ above the line connecting the posterior superior iliac spines, and the other one $5 \mathrm{~cm}$ below that line. The patient then slowly bends down as far as possible, while keeping the knees straight. The measurement is made using a tape measure. The obtained result is accurate within $0.5 \mathrm{~cm}$. The range of motion tests were carried out by the same technician and each measurement was an arithmetic mean of 5 trials. 


\section{Postural stability assessment}

Additionally, an objective measurement tool for evaluating postural stability was used. The evaluation was performed using a double-plate stabilographic platform (SP) equipped with a computer-aided posturographic system, model CQ Stab2P (CQ Electronic System, Czernica, Poland).

The measurement error was $0.86 \%$. For each patient, 2 trials were carried out: the $1^{\text {st }}$ trial with eyes open in full visual control, and the $2^{\text {nd }}$ trial with eyes closed and no visual control. The subjects were in a habitual upright position, standing barefoot on the SP (feet apart in line with their hips, arms down alongside their bodies, head facing forward, and eyes fixed on a designated point at eye level about $1.5 \mathrm{~m}$ away).

Statistical analyses of the basic posturographic parameters were conducted in order to compare balance in the tested groups of patients. The following parameters were analyzed: (1) SPAP - anterior/posterior path length in the sagittal plane [mm]; (2) SPML - medio/lateral path length in the frontal plane [mm]; (3) SA - sway area (the total sway area of the center of pressure during the 30 -second trial) $\left[\mathrm{mm}^{2}\right]$; (4) MF - mean frequency of sway in all planes $[\mathrm{Hz}]$; and (5) MV - mean velocity of sway in all planes $[\mathrm{mm} / \mathrm{s}]$.

The abovementioned measurements of posture-related parameters were made before and after the treatment process. In the second stage of the project, the measurements were repeated (along with the subjective research based on questionnaires and functional tests) as long-term results (followup) 1 and 3 months after completion of the study (during this period, the patients were not subjected to any treatment).

\section{Statistical analysis}

The results were analyzed using STATISTICA v. 10.0 software (StatSoft Inc., Tulsa, USA). The normality of sample distribution was analyzed with the Shapiro-Wilk test. The distribution of the samples in most cases were not consistent with a normal distribution, hence the use of non-parametric tests. Skewness and kurtosis (flatness) were less than 2.5 and they were unimodal distributions, therefore the arithmetic mean and standard deviation were taken as a measure of central tendency and dispersion. The homogeneity of the distribution of patients' characteristics in all groups was analyzed with the most reliable version of the $\chi^{2}$ test and the Kruskal-Wallis homogeneity test. Statistical significance was set at $\mathrm{p}<0.05$. Friedmann's ANOVA analysis was used for dependent variables, and nonparametric Kruskal-Wallis variance analysis was used for independent variables. Tukey's post hoc multiple comparisons test was used to identify the exact dependencies resulting from the variance analysis between individual groups, and the Bonferroni's post hoc test was used for analysis of multiple intra-group measurements. Statistical significance was set at $\mathrm{p}<0.05$.

\section{Results}

\section{Analysis of the Visual Analogue Scale pain intensity scores}

All the comparison groups demonstrated a statistically significant reduction in pain, as compared to the initial values, measured according to the VAS scale (Table 2).

In group A (magnetic therapy $10 \mathrm{mT}$ ), the value of pain sensations decreased during the 3 -week treatment period from 5.80 to 2.15 points on average ( $\mathrm{p}=0.0015$ in the post hoc analysis). Interestingly, at the 1-month follow-up evaluation, a further reduction of pain was observed in relation to the condition directly after the treatments from 2.15 to 1.40 points on average $(\mathrm{p}=0.0401$ in the post hoc analysis). However, at 3 months post-therapy, in relation

Table 2. Intragroup comparisons of pain intensity changes in VAS and LPS scores before and after treatment

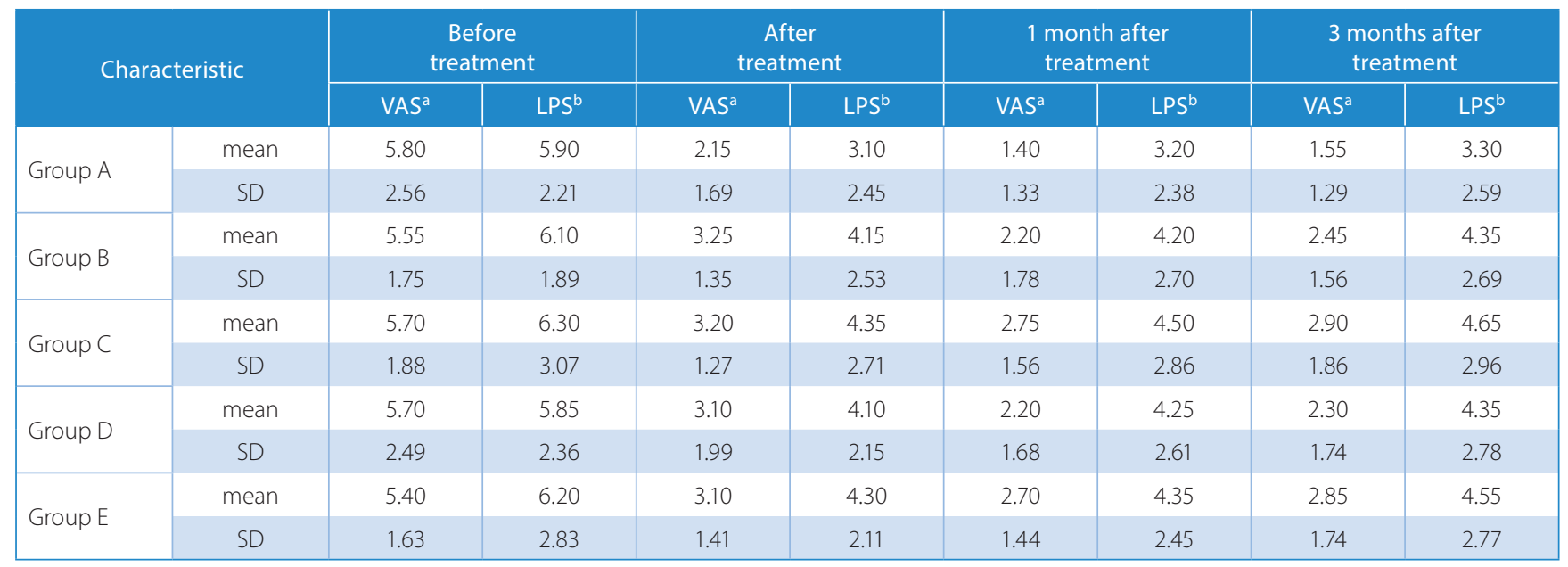

a Friedmann's ANOVA analysis (a total values of significant levels in each groups without the post hoc Bonferroni's test): group A ( $p=0.0128$ ); group $B(p=0.0380)$; group C ( $p=0.0372)$; group $D(p=0.0367)$; group $E(p=0.0370)$; ${ }^{b}$ Friedmann's ANOVA analysis (a total values of significant levels in each groups without the post hoc Bonferroni's test): group $A(p=0.0358)$; group $B(p=0.0460)$; group C ( $p=0.0471)$; group D ( $p=0.0466)$; group E ( $p=0.0478)$; VAS - Visual Analogue Scale; LPS - Laitinen Pain Scale; SD - standard deviation. 
to the value recorded at 1 month post-therapy, there was a gradual, albeit statistically insignificant, increase in the pain level (from 1.40 to 1.55 points on average, $\mathrm{p}>0.05$ in the post hoc analysis).

On the other hand, in group B (magnetic therapy $5 \mathrm{mT}$ ), during the 3-week treatment period, the recorded values of pain sensations were reduced from 5.55 to 3.25 points on average ( $p=0.0082$ in the post hoc analysis). Again, it was interesting to observe that in the follow-up evaluation at 1 month post-therapy a further reduction of pain was observed in relation to the condition directly post-treatment - from 3.25 to 2.20 points on average ( $p=0.0278$ in the post hoc analysis). However, at 3 months post-therapy, in relation to the value recorded at 1 month post-therapy, there was a gradual, statistically insignificant recurrence of pain sensations (from 2.20 to 2.45 points on average, $\mathrm{p}>0.05$ in the post hoc analysis).

In group $C$ (magnetic therapy, placebo), after 3 weeks of simulated treatments the value of pain sensations was reduced from 5.70 to 3.20 points on average $(\mathrm{p}=0.0061$ in the post hoc analysis). Here again, in the follow-up evaluation at 1 month post-therapy, a further reduction of pain was observed compared to the condition directly posttreatment - from 3.20 to 2.75 points on average ( $\mathrm{p}=0.0478$ in the post hoc analysis). Similarly to the previous groups, at 3 months post-therapy a tendency of increased pain sensations was observed as compared to the value at 1-month post-therapy (from 2.75 to 2.90 points on average, $\mathrm{p}>0.05$ in the post hoc analysis).

In group D (magnetic stimulation), during the 3-week treatment period, the index of pain sensations decreased from 5.70 to 3.10 points on average ( $\mathrm{p}=0.0052$ in the post hoc analysis). Interestingly, the follow-up evaluation at 1 month posttherapy showed a further reduction of pain in relation to the condition directly post-treatment - from 3.10 to 2.20 points on average ( $p=0.0352$ in the post hoc analysis). However, in the follow-up evaluation at 3 months post-therapy, a slight increase in pain was observed (from 2.20 to 2.30 points on average, $\mathrm{p}>0.05$ in the post hoc analysis).

In group $\mathrm{E}$ (magnetic stimulation, placebo), after 3 weeks of simulated treatments the index of pain sensations was reduced from 5.40 to 3.10 points on average ( $\mathrm{p}=0.0088$ in the post hoc analysis). Curiously, in the follow-up evaluation at 1 month post-therapy, a further change in the pain sensations was observed, as compared to the condition directly post-treatment - from 3.10 to 2.70 points on average ( $p=0.0488$ in the post hoc analysis). Similarly, at 3 months post-therapy - in relation to the value recorded at 1 month post-therapy - a statistically insignificant recurrence of pain was recorded (from 2.70 to 2.85 points on average, $\mathrm{p}>0.05$ in the post hoc analysis).

In conclusion, it may be observed that the greatest rate of progress of the therapy, as measured according to the VAS scale, occurred in all study groups within the 3-week period when kinesiotherapy and physical treatments were used (this also refers to the simulated placebo treatments).
Despite discontinuing the treatment process, the analgesic effect continued and was relatively stable. Moreover, during the 1-month period after cessation of therapy (in the follow-up observation) a further significant decrease in pain sensations was recorded in patients (despite the lack of any medical treatment). Unfortunately, the long-term results at 3-month follow-up showed a tendency, albeit statistically insignificant, of a gradual recurrence of pain in all study groups.

This means that the therapeutic progress was significant, but short-term in nature, which may be confirmed by the signs of deterioration of progress 3 months after completion of the therapeutic process.

\section{Analysis of the Laitinen Pain Scale pain intensity scores}

A similarly subjective reduction in pain was recorded using the Laitinen questionnaire (Table 2). The therapy was effective in all study groups because at each stage of the project, improvement was recorded in relation to the pretreatment condition. However, as in the case of the VAS scale, the effect was rather short-term because the followup results showed a negative trend of increasing pain sensations (in this case, an unfavorable statistical trend of deterioration occurred even 1 month post-therapy, which unfortunately continued in the subsequent measurement at 3-month follow-up).

In group A (magnetic therapy $10 \mathrm{mT}$ ) during the 3 -week treatment period, the value of pain sensations reduced from 5.90 to 3.10 points on average ( $p=0.0014$ in the post hoc analysis). At 1 month post-therapy, a slight increase in pain was observed in relation to the previous state - from 3.10 to 3.20 points on average ( $p>0.05$ in the post hoc analysis). At 3 months post-therapy, in relation to the value recorded at 1 month post-therapy, there was a further, statistically insignificant, increase (from 3.20 to 3.30 points on average, $\mathrm{p}>0.05$ in the post hoc analysis).

On the other hand, in group B (magnetic therapy $5 \mathrm{mT}$ ), during the 3-week treatment period, the assessment of pain was reduced from 6.10 to 4.15 points on average ( $\mathrm{p}=0.0092$ in the post hoc analysis). One month after the completion of therapy, however, a statistically insignificant increase in symptoms compared to the earlier state was observed - from 4.15 to 4.20 points on average ( $p>0.05$ in the post hoc analysis). At 3 months post-therapy, a further, gradual recurrence of pain sensations was recorded in relation to the value 1 month after the completion of therapy (from 4.20 to 4.35 points on average, $\mathrm{p}>0.05$ in the post hoc analysis).

In group $C$ (magnetic therapy, placebo), after 3 weeks of simulated treatments the value of pain sensations was reduced from 6.30 to 4.35 points on average ( $\mathrm{p}=0.0091$ in the post hoc analysis). Follow-up evaluation at 1 month post-therapy revealed an unfavorable, albeit insignificant, increase in pain symptoms as compared to the condition directly post-treatment - from 4.35 to 4.50 points 
on average ( $p>0.05$ in the post hoc analysis). Similarly to the previous groups, at 3 months post-therapy a further, slight increase in pain sensations was recorded in relation to the value at 1 month after the completion of therapy (from 4.50 to 4.65 points on average, $\mathrm{p}>0.05$ in the post hoc analysis).

In group D (magnetic stimulation) during the 3-week treatment period, the value of pain symptoms decreased from 5.85 to 4.10 points on average ( $p=0.0092$ in the post hoc analysis). Unfortunately, at 1 month post-therapy an increase (statistically insignificant) in symptoms was observed in relation to the previous state - from 4.10 to 4.25 points on average ( $\mathrm{p}>0.05$ in the post hoc analysis). After 3 months, a further slight increase in pain sensations was observed (from 4.25 to 4.35 points on average, $\mathrm{p}>0.05$ in the post hoc analysis).

In group $\mathrm{E}$ (magnetic stimulation, placebo), after 3 weeks of simulated treatments the value of pain sensations reduced from 6.20 to 4.30 points on average ( $p=0.0091$ in the post hoc analysis). At 1 month post-therapy, an unfavorable trend was observed in relation to the earlier state - an increase, on average, from 4.30 to 4.35 points ( $p>0.05$ in the post hoc analysis). Similarly, at 3 months post-therapy, in relation to the value recorded at 1 month post-therapy, a statistically insignificant recurrence of pain was recorded (from 4.30 to 4.55 points on average, $\mathrm{p}>0.05$ in the post hoc analysis).

The intergroup analysis we conducted demonstrates that the greatest analgesic effect was recorded in group A, where the results were significantly better than in other groups. Results obtained with an application of a magnetic field of $10 \mathrm{mT}$ were statistically significantly better than those obtained with magnetic stimulation or magnetic therapy using lower induction. The advantage of group A over the remaining groups was clearly visible at all stages of treatment. Curiously, no differences were observed between groups B (magnetic therapy $5 \mathrm{mT}$ ), C (pseudo-magnetic therapy), D (magnetic stimulation), and $\mathrm{E}$ (pseudo-magnetic stimulation), which attests to the fact that the other magnetic fields did not produce positive effects compared to the placebo methods.

This is confirmed by both the results of measurements performed using the VAS scale (Fig. 2) and by the Laitinen questionnaire (Fig. 3).

\section{Analysis of the Oswestry Disability Index functional ability scores}

After 3 weeks of therapy, all of the comparison groups demonstrated a statistically significant improvement of functional ability, as measured by the ODI (Table 3).

In group A (magnetic therapy, $10 \mathrm{mT}$ ) functional ability improved significantly during the 3 weeks of therapy ( $\mathrm{p}=0.0041$ in the post hoc analysis). The follow-up evaluation (1 month after the end of therapy) showed a statistically insignificant decrease in functional ability ( $\mathrm{p}>0.05)$. A similarly unfavorable statistical tendency also occurred in the evaluation 3 months after the end of physical therapy treatments $(p>0.05)$.The same applied to group B (magnetic therapy, $5 \mathrm{mT}$ ), where functional ability measured by the ODI had initially significantly improved after the therapy ( $\mathrm{p}=0.0225 \mathrm{in}$ the post hoc analysis). Unfortunately,

\section{VAS scoring [\%]}

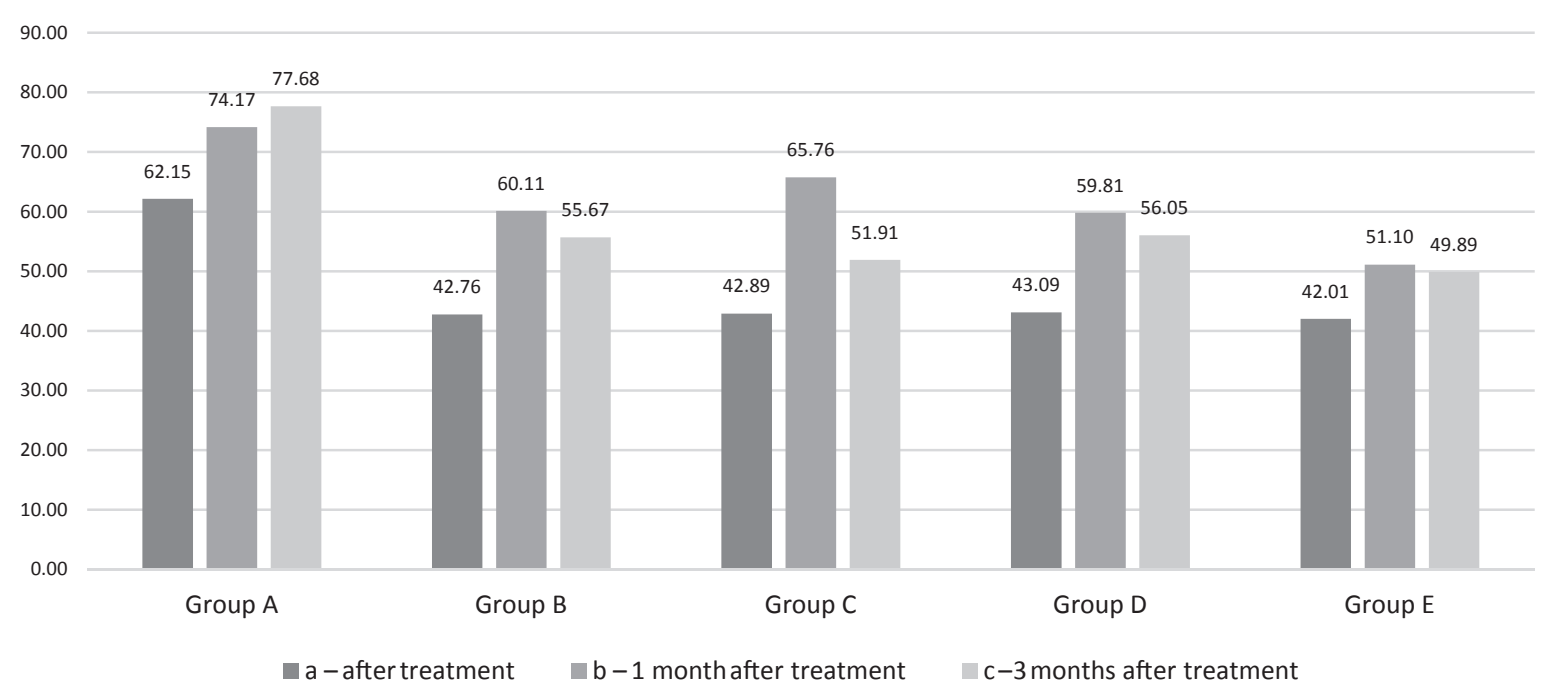

Fig. 2. Intergroup comparisons of the pain intensity reduction in VAS scoring [\%] after treatment and in follow-up analyses,

1 and 3 months after treatment

$a$ - Kruskal-Wallis ANOVA analysis $(p=0.0328)$; T Tukey's post hoc analysis: $p(A, B)=0.0122, p(A, C)=0.0188, p(A, C)=0.0224, p(A, E)=0.0122$, $p(B, C)>0.05, p(B, D)>0.05, p(B, E)>0.05, p(C, D)>0.05, p(C, E)>0.05, p(D, E)>0.05 ; b-$ Kruskal-Wallis ANOVA analysis $(p=0.0466) ; T$ Tukey's post hoc analysis: $p(A, B)=0.0380, p(A, C)=0.0182, p(A, C)=0.0224, p(A, E)=0.0122, p(B, C)>0.05, p(B, D)>0.05, p(B, E)>0.05, p(C, D)>0.05$, $p(C, E)>0.05, p(D, E)>0.05 ; C-$ Kruskal-Wallis ANOVA analysis $(p=0.0403) ;$ T Tukey's post hoc analysis: $p(A, B)=0.0280, p(A, C)=0.0166$ $p(A, C)=0.0124, p(A, E)=0.0082, p(B, C)>0.05, p(B, D)>0.05, p(B, E)>0.05, p(C, D)>0.05, p(C, E)>0.05, p(D, E)>0.05$. 


\section{LPS scoring [\%]}

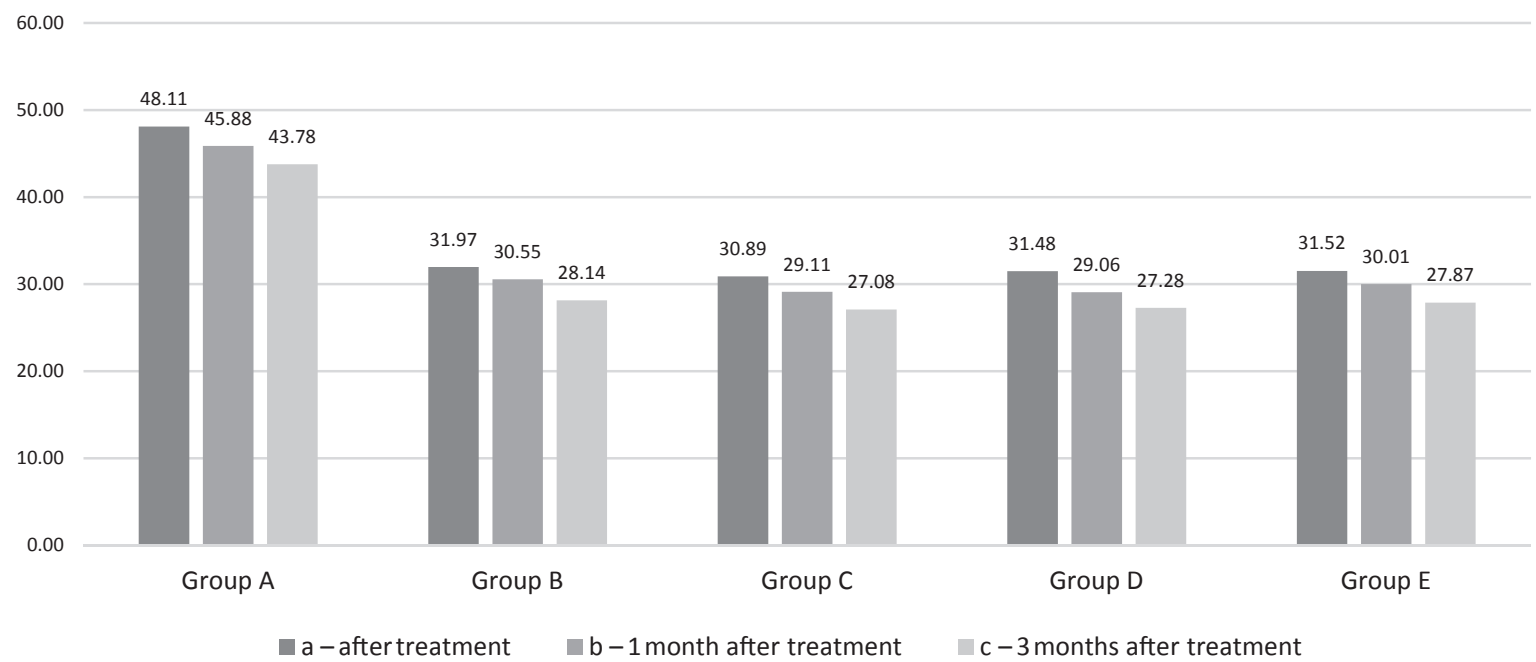

Fig. 3. Intergroup comparisons of the pain intensity reduction in LPS scoring [\%] after treatment and in follow-up analyses, 1 and 3 months after treatment

$a-$ Kruskal-Wallis ANOVA analysis $(p=0.0368)$; T Tukey's post hoc analysis: $p(A, B)=0.0228, p(A, C)=0.0122, p(A, C)=0.0260, p(A, E)=0.0272$, $p(B, C)>0.05, p(B, D)>0.05, p(B, E)>0.05, p(C, D)>0.05, p(C, E)>0.05, p(D, E)>0.05 ; b-$ Kruskal-Wallis ANOVA analysis $(p=0.0388) ; T$ Tukey's post hoc analysis: $p(A, B)=0.0208, p(A, C)=0.0380, p(A, C)=0.0382, p(A, E)=0.0182, p(B, C)>0.05, p(B, D)>0.05, p(B, E)>0.05, p(C, D)>0.05$ $p(C, E)>0.05, p(D, E)>0.05 ; C-$ Kruskal-Wallis ANOVA analysis $(p=0,0390)$; T Tukey's post hoc analysis: $p(A, B)=0.0224, p(A, C)=0.0240$, $p(A, C)=0.0270, p(A, E)=0.0270, p(B, C)>0.05, p(B, D)>0.05, p(B, E)>0.05, p(C, D)>0.05, p(C, E)>0.05, p(D, E)>0.05$.

Table 3. Intragroup comparisons of the disability level changes in ODI and RMDQ scoring before and after treatment

\begin{tabular}{|c|c|c|c|c|c|c|c|c|c|}
\hline \multirow{2}{*}{\multicolumn{2}{|c|}{ Characteristic }} & \multicolumn{2}{|c|}{$\begin{array}{c}\text { Before } \\
\text { treatment } \\
\end{array}$} & \multicolumn{2}{|c|}{$\begin{array}{c}\text { After } \\
\text { treatment } \\
\end{array}$} & \multicolumn{2}{|c|}{$\begin{array}{c}1 \text { month after } \\
\text { treatment }\end{array}$} & \multicolumn{2}{|c|}{$\begin{array}{c}3 \text { months after } \\
\text { treatment }\end{array}$} \\
\hline & & $\mathrm{ODI}^{\mathrm{a}}$ & $\mathrm{RMDQ}^{\mathrm{b}}$ & $\mathrm{ODI}^{\mathrm{a}}$ & $\mathrm{RMDQ}^{\mathrm{b}}$ & $\mathrm{ODI}^{\mathrm{a}}$ & $\mathrm{RMDQ}^{\mathrm{b}}$ & $\mathrm{ODI}^{\mathrm{a}}$ & $\mathrm{RMDQ}^{\mathrm{b}}$ \\
\hline \multirow{2}{*}{ Group A } & mean & 16.50 & 12.05 & 10.10 & 6.15 & 10.20 & 6.30 & 11.15 & 6.55 \\
\hline & SD & 8.27 & 6.18 & 6.58 & 4.88 & 6.82 & 5.28 & 7.19 & 5.54 \\
\hline \multirow{2}{*}{ Group B } & mean & 15.95 & 13.90 & 12.25 & 9.15 & 13.00 & 9.30 & 13.20 & 9.40 \\
\hline & SD & 8.12 & 7.12 & 6.44 & 5.12 & 6.43 & 5.48 & 7.87 & 6.11 \\
\hline \multirow{2}{*}{ Group C } & mean & 16.15 & 13.10 & 12.75 & 9.05 & 12.90 & 9.15 & 13.15 & 9.25 \\
\hline & SD & 7.98 & 6.65 & 6.78 & 5.18 & 7.77 & 5.55 & 10.62 & 6.72 \\
\hline \multirow{2}{*}{ Group D } & mean & 15.70 & 12.95 & 12.10 & 9.15 & 12.75 & 9.25 & 13.10 & 9.30 \\
\hline & SD & 8.41 & 6.56 & 5.72 & 5.70 & 7.53 & 5.83 & 10.82 & 7.03 \\
\hline \multirow{2}{*}{ Group E } & mean & 16.10 & 13.85 & 12.50 & 9.55 & 13.05 & 9.65 & 13.20 & 9.80 \\
\hline & SD & 8.04 & 2.16 & 6.63 & 5.53 & 7.45 & 6.05 & 9.59 & 7.09 \\
\hline
\end{tabular}

a Friedmann's ANOVA analysis (a total values of significant levels in each groups without the post hoc Bonferroni's test): group A ( $p=0.0288$ ); group B ( $p=0.0473)$; group C ( $p=0.0475)$; group D ( $p=0.0466)$; group $E(p=0.0478) ;{ }^{b}$ Friedmann's ANOVA analysis (a total values of significant levels in each groups without the post hoc Bonferroni's test): group $A(p=0.0112)$; group $B(p=0.0278)$; group $C(p=0.0291)$; group $D(p=0.0282)$; group $E(p=0.0270)$;

ODI - Oswestry Disability Index; RMDQ - Roland-Morris Disability Questionnaire; SD - standard deviation.

in the follow-up observations (at 1 month and 3 months post-therapy) the situation was reversed and a statistical trend was observed towards deterioration of functional ability in the patients $(\mathrm{p}>0.05)$.

Similarly, group C (magnetic therapy, placebo) demonstrated an intense, although short-term, improvement of the patients' ability ( $\mathrm{p}=0.0242$ in the post hoc analysis), but the process did not continue and follow-up observations showed a tendency towards a gradual weakening of the ODI $(\mathrm{p}>0.05)$.

In case of group D (magnetic stimulation), a significant increase in functional ability was detected in short-term observation ( $\mathrm{p}=0.0317$ in the post hoc analysis), but as with the previous groups, after the therapy was stopped a slight deterioration of effects occurred ( $p>0.05$ ).

In group $\mathrm{E}$ (magnetic stimulation, placebo) the recorded changes were similar, i.e., the patients' ability improved after the 3 -week therapy ( $\mathrm{p}=0.0235$ in the post hoc analysis). However, similarly to the previously discussed groups, a statistical trend reflecting a gradual recurrence of adverse symptoms occurred ( $p>0.05$ ). Detailed data concerning the Oswestry questionnaire are presented in Fig. 4. 


\section{ODI scoring [\%]}

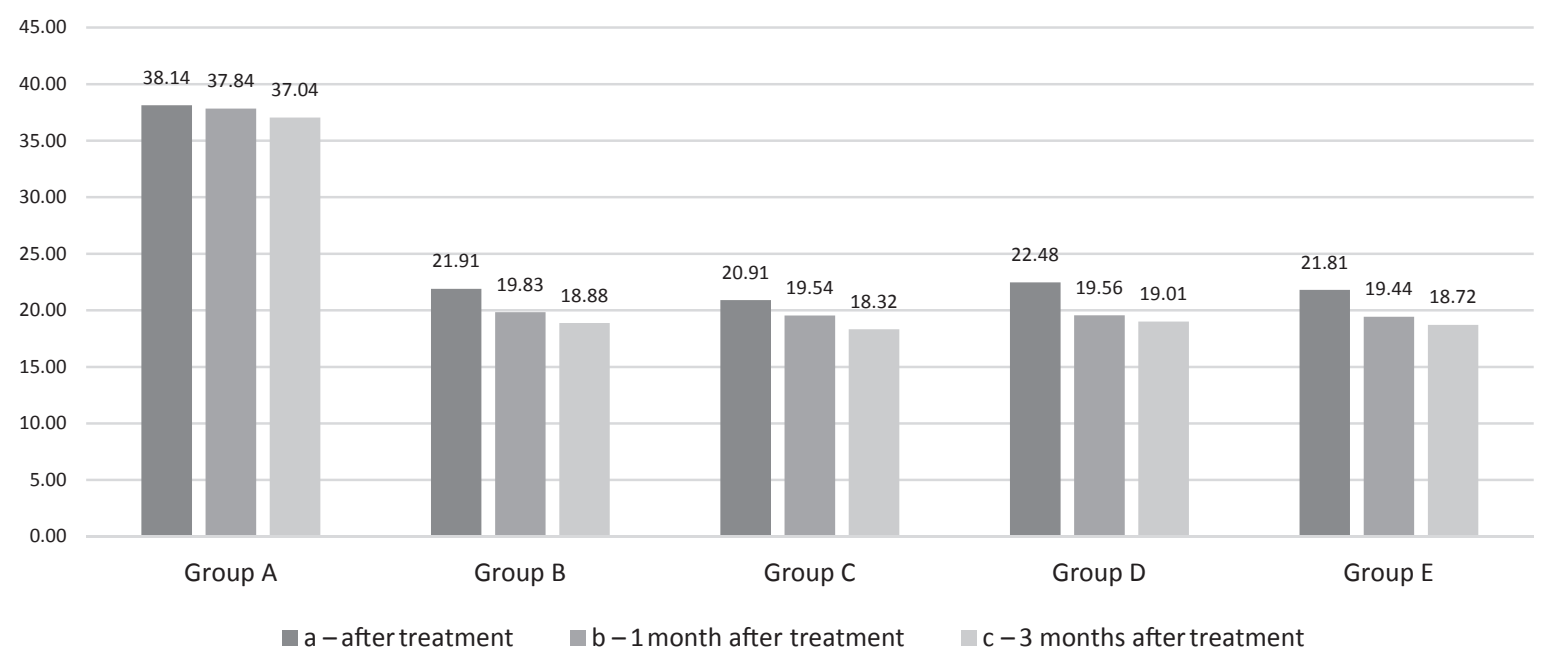

Fig. 4. Intergroup comparisons of the disability level diminishment in ODI scoring [\%] after treatment and in follow-up analyses, 1 and 3 months after treatment

$a$ - Kruskal-Wallis ANOVA analysis ( $p=0.0408$ ); T Tukey's post hoc analysis: $p(A, B)=0.0288, p(A, C)=0.0220, p(A, C)=0.0298, p(A, E)=0.0292$, $p(B, C)>0.05, p(B, D)>0.05, p(B, E)>0.05, p(C, D)>0.05, p(C, E)>0.05, p(D, E)>0.05 ; b-$ Kruskal-Wallis ANOVA analysis $(p=0.0408) ; T$ Tukey's post hoc analysis: $p(A, B)=0.0288, p(A, C)=0.0220, p(A, C)=0.0298, p(A, E=0.0292, p(B, C)>0.05, p(B, D)>0.05, p(B, E)>0.05, p(C, D)>0.05$, $p(C, E)>0.05, p(D, E)>0.05 ; C-$ Kruskal-Wallis ANOVA analysis $(p=0.0455)$; T Tukey's post hoc analysis: $p(A, B)=0.0305, p(A, C)=0.0288$, $p(A, C)=0.0341, p(A, E)=0.0312, p(B, C)>0.05, p(B, D)>0.05, p(B, E)>0.05, p(C, D)>0.05, p(C, E)>0.05, p(D, E)>0.05$.

\section{RMDQ scoring [\%]}

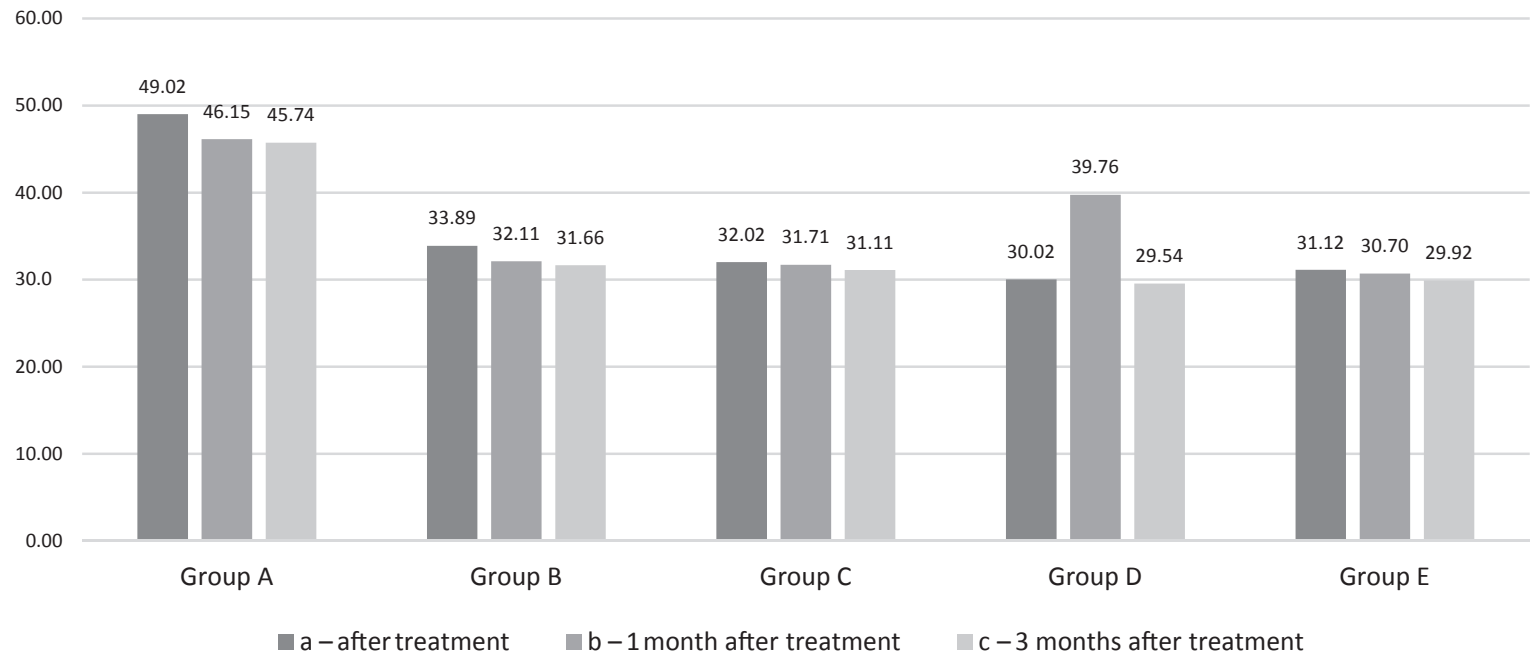

Fig. 5. Intergroup comparisons of the disability level diminishment in RMDQ scoring [\%] after treatment and in follow-up analyses, 1 and 3 months after treatment

a - Kruskal-Wallis ANOVA analysis $(p=0.0388$ ); T Tukey's post hoc analysis: $p(A, B)=0.0320, p(A, C)=0.0212, p(A, C)=0.0208, p(A, E)=0.0256$, $p(B, C)>0.05, p(B, D)>0.05, p(B, E)>0.05, p(C, D)>0.05, p(C, E)>0.05, p(D, E)>0.05 ; b-$ Kruskal-Wallis ANOVA analysis $(p=0.0466) ; T$ Tukey's post hoc analysis: $p(A, B)=0.0310, p(A, C)=0.0317, p(A, C)=0.0268, p(A, E)=0.0286, p(B, C)>0.05, p(B, D)>0.05, p(B, E)>0.05, p(C, D)>0.05$, $p(C, E)>0.05, p(D, E)>0.05 ; C-$ Kruskal-Wallis ANOVA analysis $(p=0.0443)$; T Tukey's post hoc analysis: $p(A, B)=0.0330, p(A, C)=0.0347$, $p(A, C)=0.0298, p(A, E)=0.0306, p(B, C)>0.05, p(B, D)>0.05, p(B, E)>0.05, p(C, D)>0.05, p(C, E)>0.05, p(D, E)>0.05$.

\section{Analysis of the Roland-Morris Disability Questionnaire functional ability scores}

Similar conclusions may be drawn from the analysis of results concerning the degree of disability assessed by the Roland-Morris questionnaire (Table 3). In all of the studied groups, significant therapeutic progress was recorded in the short-term observation. Values of the significance levels from the post hoc analysis were $p=0.0014$ for group $\mathrm{A} ; \mathrm{p}=0.0173$ for group $\mathrm{B} ; \mathrm{p}=0.0184$ for group $\mathrm{C}$; $\mathrm{p}=0.0182$ for group $\mathrm{D}$; and $\mathrm{p}=0.0174$ for group $\mathrm{E}$. However, the long-term follow-up observation unfortunately 
showed a statistical tendency towards an increase in disability ( $\mathrm{p}>0.05)$.

As was the case with pain sensations and with regard to the influence of magnetic fields on physical fitness of patients with lumbosacral discopathy, there was a significant advantage of magnetic therapy with an induction of $10 \mathrm{mT}$. In the other groups, the results obtained were statistically significantly worse. Also, no differences were observed between groups B, C, D, and E, which suggests that exposure to magnetic stimulation and magnetic therapy with an intensity of $5 \mathrm{mT}$ failed to meet expectations in comparison with the placebo groups.

Detailed data concerning the Roland-Morris questionnaire are presented in Fig. 5.

\section{Analysis of results of the Lasègue hip mobility test}

When evaluating changes in the mobility of the hip joint (measured by the Lasègue test) it must be noted that clinical improvement occurred in all study groups (Table 4).

After 15 treatments, Group A (magnetic therapy, $10 \mathrm{mT}$ ) demonstrated in the Lasègue test a statistically significant improvement in mobility compared to their pre-therapy results ( $\mathrm{p}=0.0102$ in the post hoc analysis). The results were similar in other comparison groups, although the changes occurred with a lower level of significance: $p=0.0323$ for group $B ; p=0.330$ for group $C ; p=0.0342$ for group $D$; and $p=0.0338$ for group E. Consequently, as was the case with the parameters studied before, the long-term followup results (at 1 month and 3 months post-therapy) also reflected a statistical tendency attesting to a gradual recurrence of limited mobility in the lumbosacral section of the spine ( $\mathrm{p}>0.05)$.

\section{Analysis of results of the Schober low back mobility test}

In case of mobility measured by the Schober test, it was found that the range of motion improved in all groups, but the observed changes were of no statistical significance. Only in group A (magnetic therapy, $10 \mathrm{mT}$ ) did the improvement in spine mobility approach the significance threshold (Table 4). In group A, the post hoc analysis indicated the following findings: an increase of mobility from $\mathrm{p}=0.0588$ (directly post-therapy), a decrease of mobility from $\mathrm{p}>0.05$ (at 1 month post-therapy) and a further decrease of mobility from $\mathrm{p}>0.05$ (at 3 months post-therapy). In the remaining groups, the changes were of similar nature, but in no case did they approach the statistical significance threshold.

After carrying out an intergroup analysis of variance, it was found that the increase in the range of motion was most prominent in group A (magnetic therapy, $10 \mathrm{mT}$ ) which achieved an advantage over the other groups. Once again, no statistically significant differences were observed between groups B, C, D, and E. Intergroup comparisons (in \%) regarding the Lasègue test and the Schober test are presented in Fig. 6 and 7.

\section{Analysis of results of the stabilographic platform postural stability test}

After the completion of the therapy process, tests on the stabilometric platform showed some improvement of balance in all patients compared to their initial state. The parameters were lower in all comparison groups, both with eyes open and eyes closed. However, in the study groups the changes were not significant, so only a certain statistical tendency can be declared here. When evaluating the

Table 4. Intragroup comparisons of hip joint mobility changes in LaT testing [degree] and changes in spine mobility at the lower Th in ShT testing [cm] before and after treatment

\begin{tabular}{|c|c|c|c|c|c|c|c|c|c|}
\hline \multirow{2}{*}{\multicolumn{2}{|c|}{ Characteristic }} & \multicolumn{2}{|c|}{$\begin{array}{l}\text { Before } \\
\text { treatment }\end{array}$} & \multicolumn{2}{|c|}{$\begin{array}{c}\text { After } \\
\text { treatment }\end{array}$} & \multicolumn{2}{|c|}{$\begin{array}{l}1 \text { month after } \\
\text { treatment }\end{array}$} & \multicolumn{2}{|c|}{$\begin{array}{c}3 \text { months after } \\
\text { treatment }\end{array}$} \\
\hline & & $\mathrm{LaT}^{\mathrm{a}}$ & $\mathrm{ShT}^{\mathrm{b}}$ & $\mathrm{LaT}^{\mathrm{a}}$ & $\mathrm{ShT}^{\mathrm{b}}$ & $\mathrm{LaT}^{\mathrm{a}}$ & $\mathrm{ShT}^{\mathrm{b}}$ & $\mathrm{LaT}^{\mathrm{a}}$ & $\mathrm{ShT}^{\mathrm{b}}$ \\
\hline \multirow{2}{*}{ Group A } & mean & 62.15 & 2.15 & 80.10 & 3.45 & 77.90 & 3.30 & 75.85 & 3.00 \\
\hline & SD & 10.45 & 1.12 & 18.33 & 2.67 & 17.89 & 2.84 & 18.64 & 2.89 \\
\hline \multirow{2}{*}{ Group B } & mean & 60.95 & 2.25 & 70.15 & 3.05 & 68.35 & 2.75 & 66.55 & 2.55 \\
\hline & SD & 10.33 & 1.89 & 17.73 & 2.70 & 18.40 & 2.05 & 18.89 & 2.09 \\
\hline \multirow{2}{*}{ Group C } & mean & 61.45 & 2.25 & 71.15 & 3.05 & 68.05 & 2.65 & 67.05 & 2.60 \\
\hline & SD & 10.74 & 1.77 & 18.44 & 2.23 & 19.39 & 2.33 & 19.11 & 2.13 \\
\hline \multirow{2}{*}{ Group D } & mean & 63.05 & 2.30 & 72.05 & 3.10 & 69.75 & 3.05 & 67.80 & 2.80 \\
\hline & SD & 11.21 & 1.21 & 17.70 & 2.74 & 16.79 & 2.45 & 16.63 & 2.39 \\
\hline \multirow{2}{*}{ Group E } & mean & 62.55 & 2.25 & 71.65 & 2.95 & 69.55 & 2.85 & 67.85 & 2.85 \\
\hline & SD & 10.56 & 1.59 & 16.44 & 2.04 & 16.65 & 2.11 & 16.89 & 2.09 \\
\hline
\end{tabular}

a Friedmann's ANOVA analysis (a total values of significant levels in each groups without the post hoc Bonferroni's test): group A ( $p=0.0322$ );

group B ( $p=0.0488)$; group C ( $=0.0491)$; group D $(p=0.0484)$; group $E(p=0.0485) ;{ }^{b}$ Friedmann's ANOVA analysis (a total values of significant levels in each groups without the post hoc Bonferroni's test): group $A(p>0.05)$; group B ( $>>0.05)$; group C ( $>>0.05)$; group D ( $p>0.05)$; group E ( $p>0.05)$; LaT - Lasègue testing; ShT - Schober testing; SD - standard deviation. 


\section{Lasègue testing [\%]}

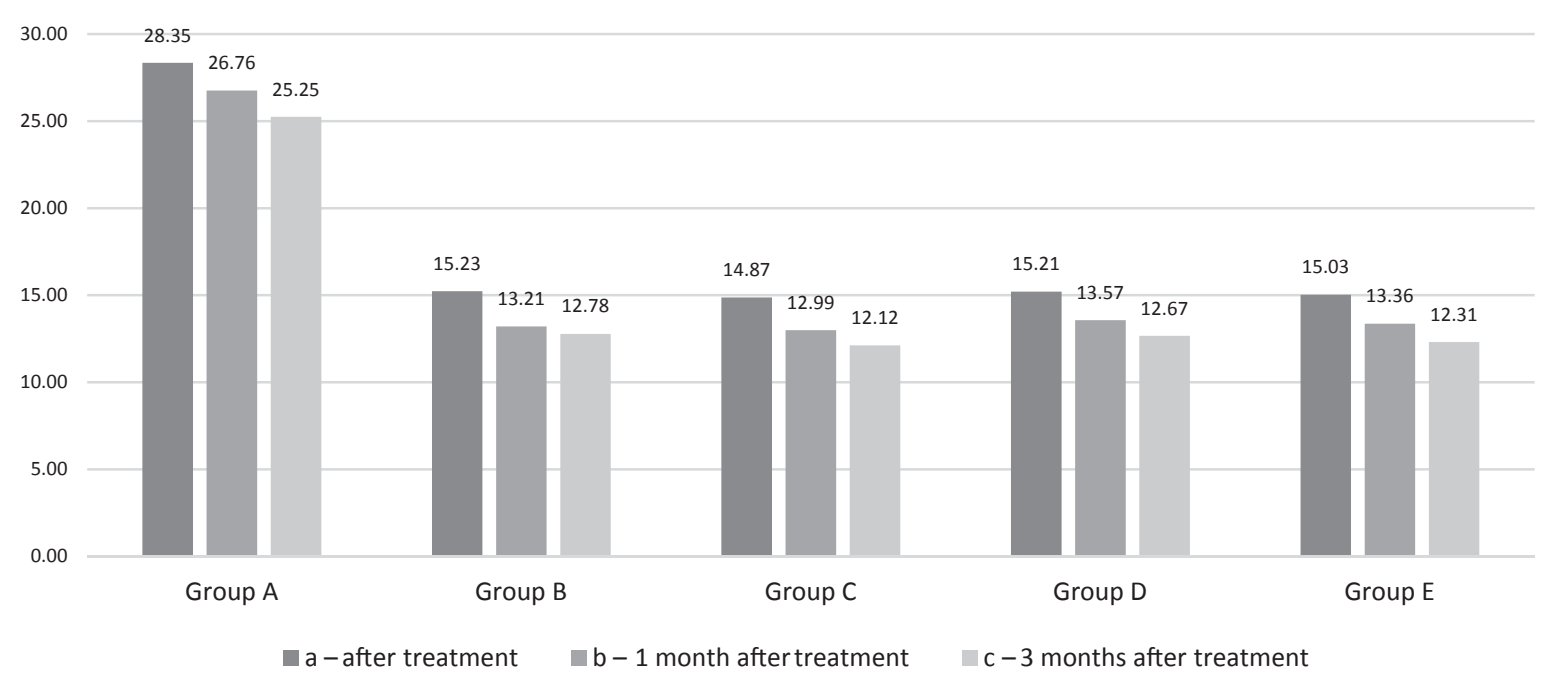

Fig. 6. Intergroup comparisons of hip joint mobility improvement in Lasègue testing [\%] after treatment and in follow-up analyses, 1 and 3 months after treatment

$a-$ Kruskal-Wallis ANOVA analysis $(p=0.0313)$; T Tukey's post hoc analysis: $p(A, B)=0.0269, p(A, C)=0.0145, p(A, C)=0.0270, p(A, E)=0.0188$, $p(B, C)>0.05, p(B, D)>0.05, p(B, E)>0.05, p(C, D)>0.05, p(C, E)>0.05, p(D, E)>0.05 ; b-$ Kruskal-Wallis ANOVA analysis $(p=0.0322) ; T$ Tukey's post hoc analysis: $p(A, B)=0.0270, p(A, C)=0.0166, p(A, C)=0.0279, p(A, E)=0.0301, p(B, C)>0.05, p(B, D)>0.05, p(B, E)>0.05, p(C, D)>0.05$, $p(C, E)>0.05, p(D, E)>0.05 ; C-$ Kruskal-Wallis ANOVA analysis $(p=0.0308) ; T$ Tukey's post hoc analysis: $p(A, B)=0.0188, p(A, C)=0.0216$, $p(A, C)=0.0209, p(A, E)=0.0101, p(B, C)>0.05, p(B, D)>0.05, p(B, E)>0.05, p(C, D)>0.05, p(C, E)>0.05, p(D, E)>0.05$.

\section{Schober testing [\%]}

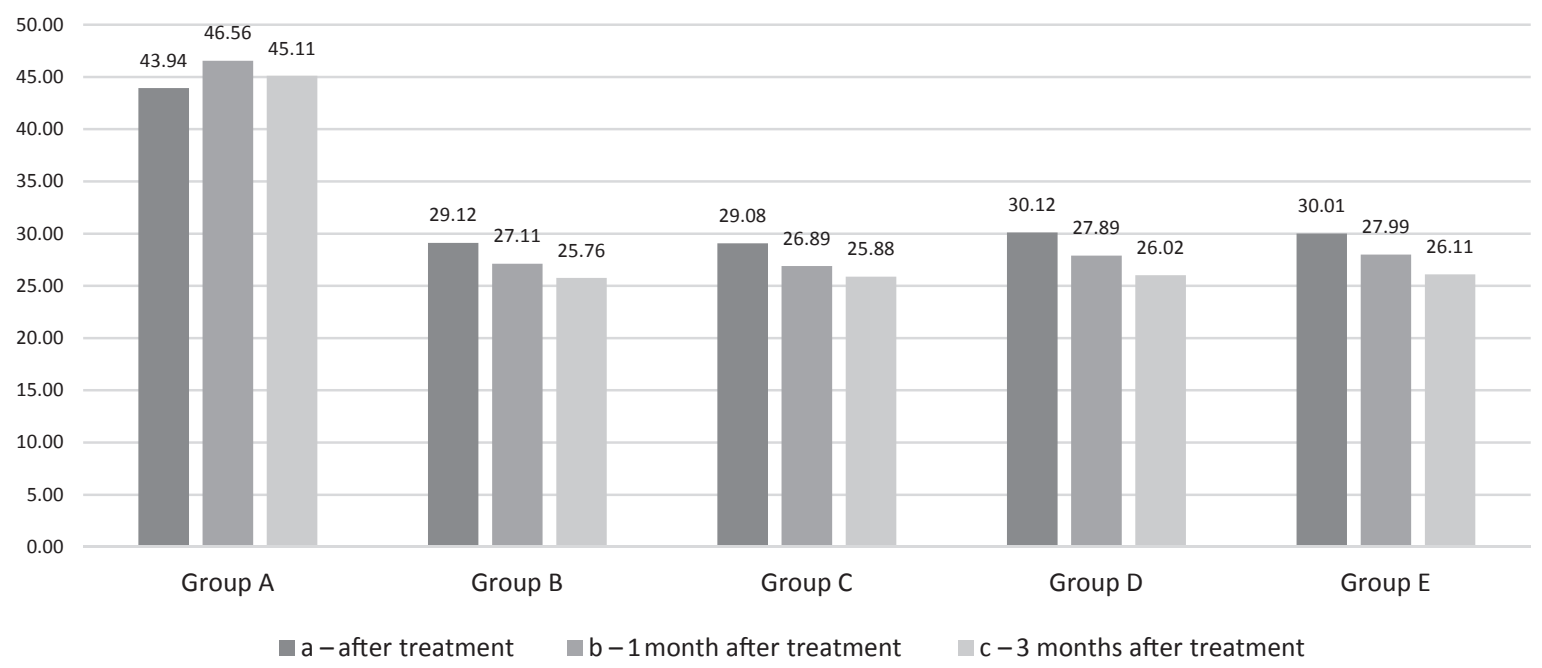

Fig. 7. Intergroup comparisons of spine mobility at the lower Th in Schober testing [\%] after treatment and in follow-up analyses, 1 and 3 months after treatment

$a-$ Kruskal-Wallis ANOVA analysis $(p=0.0289)$; T Tukey's post hoc analysis: $p(A, B)=0.0210, p(A, C)=0.0122, p(A, C)=0.0202, p(A, E)=0.0102$, $p(B, C)>0.05, p(B, D)>0.05, p(B, E)>0.05, p(C, D)>0.05, p(C, E)>0.05, p(D, E)>0.05 ; b-$ Kruskal-Wallis ANOVA analysis $(p=0.0277) ; T$ Tukey's post hoc analysis: $p(A, B)=0.0103, p(A, C)=0.0106, p(A, C)=0.0280, p(A, E)=0.0288, p(B, C)>0.05, p(B, D)>0.05, p(B, E)>0.05, p(C, D)>0.05$, $p(C, E)>0.05, p(D, E)>0.05 ; c-$ Kruskal-Wallis ANOVA analysis $(p=0.0318) ; T$ Tukey's post hoc analysis: $p(A, B)=0.0177, p(A, C)=0.0219$, $p(A, C)=0.0276, p(A, E)=0.0110, p(B, C)>0.05, p(B, D)>0.05, p(B, E)>0.05, p(C, D)>0.05, p(C, E)>0.05, p(D, E)>0.05$.

results pre- and post-therapy without statistical analysis, it appears that a beneficial reduction of posturographic indicators took place, particularly in group A. Long-term follow-up observations showed tendencies for the deterioration of body posture in all of the studied parameters, although these changes were also statistically insignificant. Some indicators after 3 months nearly returned to the state prior to the therapy. In the Kruskal-Wallis analysis of variance (ANOVA), no intergroup differences were observed ( $p>0.05$ ). That is why only the results of the analysis of variance for dependent variables are shown below, reflecting certain statistical tendencies in each of the groups (Tables 5-9). 
Table 5. Intragroup comparisons of the total path length parameter (SP) changes in stabilometric examination with open and closed eyes before and after treatment $[\mathrm{mm}]$

\begin{tabular}{|c|c|c|c|c|c|c|c|c|c|}
\hline \multirow{2}{*}{\multicolumn{2}{|c|}{ Characteristic }} & \multicolumn{2}{|c|}{$\begin{array}{l}\text { Before } \\
\text { treatment }\end{array}$} & \multicolumn{2}{|c|}{$\begin{array}{c}\text { After } \\
\text { treatment }\end{array}$} & \multicolumn{2}{|c|}{$\begin{array}{l}1 \text { month after } \\
\text { treatment }\end{array}$} & \multicolumn{2}{|c|}{$\begin{array}{c}3 \text { months after } \\
\text { treatment }\end{array}$} \\
\hline & & open $^{a}$ & closed $^{\mathrm{b}}$ & open $^{\mathrm{a}}$ & closed $^{b}$ & open $^{\mathrm{a}}$ & closed $^{\mathrm{b}}$ & open $^{a}$ & closed $^{\mathrm{b}}$ \\
\hline \multirow{2}{*}{ Group A } & mean & 125.12 & 184.22 & 117.56 & 176.43 & 122.45 & 180.02 & 124.67 & 181.17 \\
\hline & SD & 90.11 & 158.11 & 110.58 & 167.22 & 112.67 & 170.89 & 120.34 & 177.24 \\
\hline \multirow{2}{*}{ Group B } & mean & 125.19 & 175.22 & 123.65 & 171.66 & 123.87 & 173.42 & 125.02 & 175.20 \\
\hline & SD & 98.45 & 128.33 & 100.21 & 150.19 & 110.89 & 162.83 & 111.02 & 162.32 \\
\hline \multirow{2}{*}{ Group C } & mean & 120.89 & 178.19 & 118.56 & 174.42 & 120.03 & 176.66 & 120.15 & 177.72 \\
\hline & SD & 104.12 & 153.77 & 116.74 & 161.32 & 118.21 & 160.99 & 118.54 & 164.44 \\
\hline \multirow{2}{*}{ Group D } & mean & 123.17 & 182.65 & 120.34 & 178.11 & 121.53 & 180.63 & 122.90 & 181.59 \\
\hline & SD & 91.22 & 140.28 & 100.72 & 132.34 & 100.45 & 150.15 & 112.03 & 152.67 \\
\hline \multirow{2}{*}{ Group E } & mean & 124.03 & 181.12 & 121.22 & 177.89 & 122.11 & 179.02 & 123.83 & 180.89 \\
\hline & SD & 93.82 & 139.99 & 98.12 & 136.02 & 107.56 & 150.33 & 111.63 & 159.78 \\
\hline
\end{tabular}

a Friedmann's ANOVA analysis (a total values of significant levels in each groups without the post hoc Bonferroni's test): group A ( $p>0.05$ );

group B ( $p>0.05)$; group C ( $p>0.05)$; group D ( $p>0.05)$; group E ( $p>0.05)$; ${ }^{b}$ Friedmann's ANOVA analysis (a total values of significant levels in each groups without the post hoc Bonferroni's test): group A ( $p>0.05)$; group B ( $p>0.05)$; group C $(p>0.05)$; group D ( $p>0.05)$; group E $(p>0.05)$.

Table 6. Intragroup comparisons of the statokinesiogram path length (SPAP) changes on the frontal plane in stabilometric examination with open and closed eyes before and after treatment [mm]

\begin{tabular}{|c|c|c|c|c|c|c|c|c|c|}
\hline \multirow{2}{*}{\multicolumn{2}{|c|}{ Characteristic }} & \multicolumn{2}{|c|}{$\begin{array}{l}\text { Before } \\
\text { treatment }\end{array}$} & \multicolumn{2}{|c|}{$\begin{array}{l}\text { After } \\
\text { treatment }\end{array}$} & \multicolumn{2}{|c|}{$\begin{array}{l}1 \text { month after } \\
\text { treatment }\end{array}$} & \multicolumn{2}{|c|}{$\begin{array}{c}3 \text { months after } \\
\text { treatment }\end{array}$} \\
\hline & & open $^{a}$ & closed $^{b}$ & open $^{a}$ & closed $^{\mathrm{b}}$ & open $^{a}$ & closed $^{\mathrm{b}}$ & open $^{\mathrm{a}}$ & closed $^{\mathrm{b}}$ \\
\hline \multirow{2}{*}{ Group A } & mean & 101.49 & 112.34 & 94.06 & 102.46 & 95.89 & 106.22 & 98.22 & 108.43 \\
\hline & SD & 80.23 & 90.23 & 86.88 & 94.34 & 82.77 & 100.84 & 85.66 & 100.98 \\
\hline \multirow{2}{*}{ Group B } & mean & 100.21 & 110.91 & 97.99 & 107.99 & 99.02 & 110.01 & 100.60 & 110.69 \\
\hline & SD & 82.39 & 82.39 & 83.55 & 88.46 & 86.44 & 100.04 & 80.01 & 107.67 \\
\hline \multirow{2}{*}{ Group C } & mean & 102.88 & 112.01 & 99.02 & 109.41 & 99.96 & 110.56 & 101.21 & 111.12 \\
\hline & SD & 85.02 & 94.12 & 83.33 & 96.45 & 85.81 & 102.82 & 89.16 & 108.89 \\
\hline \multirow{2}{*}{ Group D } & mean & 102.63 & 112.31 & 99.11 & 108.99 & 101.54 & 111.04 & 102.09 & 111.79 \\
\hline & SD & 84.12 & 104.63 & 83.54 & 100.45 & 87.77 & 100.54 & 80.87 & 110.97 \\
\hline \multirow{2}{*}{ Group E } & mean & 100.95 & 111.54 & 97.92 & 109.92 & 98.82 & 110.83 & 100.09 & 112.32 \\
\hline & SD & 80.95 & 90.99 & 82.32 & 94.02 & 81.29 & 94.54 & 80.84 & 99.46 \\
\hline
\end{tabular}

a Friedmann's ANOVA analysis (a total values of significant levels in each groups without the post hoc Bonferroni's test): group A ( $p>0.05$ ); group $B(p>0.05)$; group C ( $p>0.05)$; group D ( $p>0.05)$; group E ( $p>0.05)$; ${ }^{b}$ Friedmann's ANOVA analysis (a total values of significant levels in each groups without the post hoc Bonferroni's test): group A ( $p>0.05)$; group B $(p>0.05)$; group C $(p>0.05)$; group D ( $p>0.05)$; group E ( $p>0.05)$.

\section{Discussion}

The present study is certainly innovative, as it presents an unequivocal evaluation of the efficacy of magnetic therapy (with different induction output values) and magnetic stimulation in the treatment of lumbar discopathy at L5-S1 within a single, prospective, randomized clinical trial based on a strict protocol of inclusion and exclusion criteria, using modern objective and subjective measurements, and accompanied by a uniform statistical analysis and observation of the long-term effects. To date, none of the authors of the available literature has carried out such a wide-ranging research project on the application of magnetic fields in therapy of low back pain in accordance with the guidelines of Evidence Based Medicine and Physiotherapy (EBM\&P).
The present study was the first such attempt in the literature. Thus, it has been difficult to refer the results to any published articles, especially with regard to body balance tests using a stabilometric platform. Moreover, no existing study on physical therapy of low back pain has carried out such detailed diagnostics or classification based on the radiological Modic assessment criteria. This allowed for a very representative population to be recruited for the purpose of this project. A crucial element of the study was also the use of simulated treatments and the fact that it was a single blind trial, which has significantly raised the profile of the study and strengthened the reliability of its conclusions. In this study, only one application of magnetic fields demonstrated certain medical efficacy, namely the magnetic therapy with the following parameters: magnetic 
Table 7. Intragroup comparisons of the sway area (SA) of the center of pressure changes in stabilometric examination with open and closed eyes before and after treatment $\left[\mathrm{mm}^{2}\right]$

\begin{tabular}{|c|c|c|c|c|c|c|c|c|c|}
\hline \multirow{2}{*}{\multicolumn{2}{|c|}{ Characteristic }} & \multicolumn{2}{|c|}{$\begin{array}{c}\text { Before } \\
\text { treatment }\end{array}$} & \multicolumn{2}{|c|}{$\begin{array}{c}\text { After } \\
\text { treatment }\end{array}$} & \multicolumn{2}{|c|}{$\begin{array}{c}1 \text { month after } \\
\text { treatment }\end{array}$} & \multicolumn{2}{|c|}{$\begin{array}{c}3 \text { months after } \\
\text { treatment }\end{array}$} \\
\hline & & open $^{\mathrm{a}}$ & closed $^{\mathrm{b}}$ & open $^{a}$ & closed $^{b}$ & open $^{a}$ & closed $^{b}$ & open $^{\mathrm{a}}$ & closed $^{b}$ \\
\hline \multirow{2}{*}{ Group A } & mean & 124.55 & 201.34 & 112.06 & 187.65 & 116.11 & 193.12 & 118.40 & 198.55 \\
\hline & SD & 75.04 & 105.33 & 71.21 & 106.12 & 75.41 & 109.19 & 75.23 & 108.35 \\
\hline \multirow{2}{*}{ Group B } & mean & 120.41 & 205.16 & 117.69 & 197.92 & 120.33 & 200.98 & 120.79 & 202.29 \\
\hline & SD & 70.21 & 108.14 & 79.62 & 105.33 & 80.94 & 100.98 & 80.97 & 100.02 \\
\hline \multirow{2}{*}{ Group C } & mean & 122.41 & 200.66 & 119.03 & 194.37 & 120.38 & 198.88 & 120.78 & 200.02 \\
\hline & SD & 64.87 & 102.33 & 68.53 & 103.32 & 70.82 & 104.99 & 70.09 & 101.32 \\
\hline \multirow{2}{*}{ Group D } & mean & 123.14 & 203.67 & 119.79 & 198.09 & 121.01 & 199.89 & 121.89 & 202.33 \\
\hline & SD & 64.33 & 104.11 & 96.87 & 102.07 & 74.94 & 103.42 & 74.08 & 104.83 \\
\hline \multirow{2}{*}{ Group E } & mean & 122.08 & 205.01 & 119.02 & 199.92 & 120.39 & 201.91 & 121.82 & 204.04 \\
\hline & SD & 80.02 & 100.23 & 80.21 & 106.11 & 81.41 & 109.13 & 81.55 & 113.88 \\
\hline
\end{tabular}

a Friedmann's ANOVA analysis (a total values of significant levels in each groups without the post hoc Bonferroni's test): group A ( $p>0.05$ );

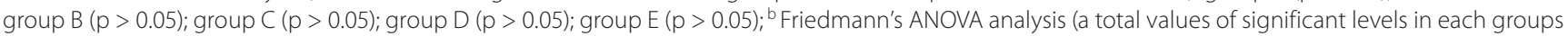
without the post hoc Bonferroni's test): group A ( $p>0.05)$; group B $(p>0.05)$; group C $(p>0.05)$; group D ( $p>0.05)$; group E ( $p>0.05)$.

Table 8. Intragroup comparisons of the mean frequency (MF) of sway in all planes changes in stabilometric examination with open and closed eyes before and after treatment $[\mathrm{Hz}]$

\begin{tabular}{|c|c|c|c|c|c|c|c|c|c|}
\hline \multirow{2}{*}{\multicolumn{2}{|c|}{ Characteristic }} & \multicolumn{2}{|c|}{$\begin{array}{l}\text { Before } \\
\text { treatment }\end{array}$} & \multicolumn{2}{|c|}{$\begin{array}{c}\text { After } \\
\text { treatment }\end{array}$} & \multicolumn{2}{|c|}{$\begin{array}{l}1 \text { month after } \\
\text { treatment }\end{array}$} & \multicolumn{2}{|c|}{$\begin{array}{c}3 \text { months after } \\
\text { treatment }\end{array}$} \\
\hline & & open $^{a}$ & closed $^{b}$ & open $^{a}$ & closed $^{\mathrm{b}}$ & open $^{a}$ & closed $^{b}$ & open $^{\mathrm{a}}$ & closed $^{\mathrm{b}}$ \\
\hline \multirow{2}{*}{ Group A } & mean & 0.34 & 0.44 & 0.28 & 0.40 & 0.31 & 0.41 & 0.36 & 0.41 \\
\hline & SD & 0.23 & 0.33 & 0.22 & 0.33 & 0.28 & 0.32 & 0.35 & 0.30 \\
\hline \multirow{2}{*}{ Group B } & mean & 0.33 & 0.46 & 0.30 & 0.45 & 0.32 & 0.45 & 0.32 & 0.45 \\
\hline & SD & 0.18 & 0.38 & 0.23 & 0.37 & 0.30 & 0.40 & 0.30 & 0.42 \\
\hline \multirow{2}{*}{ Group C } & mean & 0.36 & 0.44 & 0.34 & 0.42 & 0.35 & 0.45 & 0.36 & 0.45 \\
\hline & SD & 0.23 & 0.30 & 0.22 & 0.31 & 0.31 & 0.36 & 0.33 & 0.44 \\
\hline \multirow{2}{*}{ Group D } & mean & 0.34 & 0.44 & 0.33 & 0.43 & 0.33 & 0.43 & 0.33 & 0.43 \\
\hline & SD & 0.21 & 0.31 & 0.24 & 0.32 & 0.26 & 0.42 & 0.26 & 0.43 \\
\hline \multirow{2}{*}{ Group E } & mean & 0.31 & 0.46 & 0.28 & 0.42 & 0.30 & 0.44 & 0.34 & 0.44 \\
\hline & SD & 0.20 & 0.37 & 0.20 & 0.39 & 0.23 & 0.36 & 0.24 & 0.36 \\
\hline
\end{tabular}

a Friedmann's ANOVA analysis (a total values of significant levels in each groups without the post hoc Bonferroni's test): group A ( $p>0.05$ ); group B ( $p>0.05)$; group C ( $p>0.05)$; group D ( $p>0.05)$; group E ( $p>0.05)$; ${ }^{b}$ Friedmann's ANOVA analysis (a total values of significant levels in each groups without the post hoc Bonferroni's test): group A ( $>>0.05)$; group B $(p>0.05)$; group C $(p>0.05)$; group D ( $>>0.05)$; group E ( $>0.05)$.

induction of $10 \mathrm{mT}$, frequency of $50 \mathrm{~Hz}$ and a single treatment duration of $20 \mathrm{~min}$. Under the influence of the above physical stimuli, the most prominent analgesic effect was observed in the improvement of mobility and functional ability of the spine, but also to a lesser extent in the improvement of parameters related to the balance of the patients.

It is also worth noting that the effects of the applied therapy were mostly short-term, as recurrent symptoms were observed in the majority of measured indicators at 1 month and 3 months post-therapy. This means that the physical treatment selected for the purposes of the study may only have an acute effect, although it shows a high efficacy in short-term observation.

It is probable that continuation of the stabilization training may have achieved a more sustainable improvement with physical therapy. It is certainly an interesting challenge for future scientific research. Unfortunately, application of magnetic therapy with a low induction value of $5 \mathrm{mT}$, and of magnetic stimulation, which is immensely popular in clinical practice, proved pointless in the treatment of symptoms of chronic lumbosacral discopathy. The use of these physical treatments contributed nothing to the therapeutic process, and the achieved effects, in comparison with the placebo methods, failed to meet expectations and cast serious doubt on the possibility of using these magnetic fields in the treatment of low back pain in accordance with the principles of modern science and medicine.

When analyzing the available literature regarding the application of magnetic fields in the treatment of patients with L5-S1 discopathy, one may notice that a majority 
Table 9. Intragroup comparisons of the mean velocity (MV) of sway in all planes changes in stabilometric examination with open and closed eyes before and after treatment $[\mathrm{mm} / \mathrm{s}]$

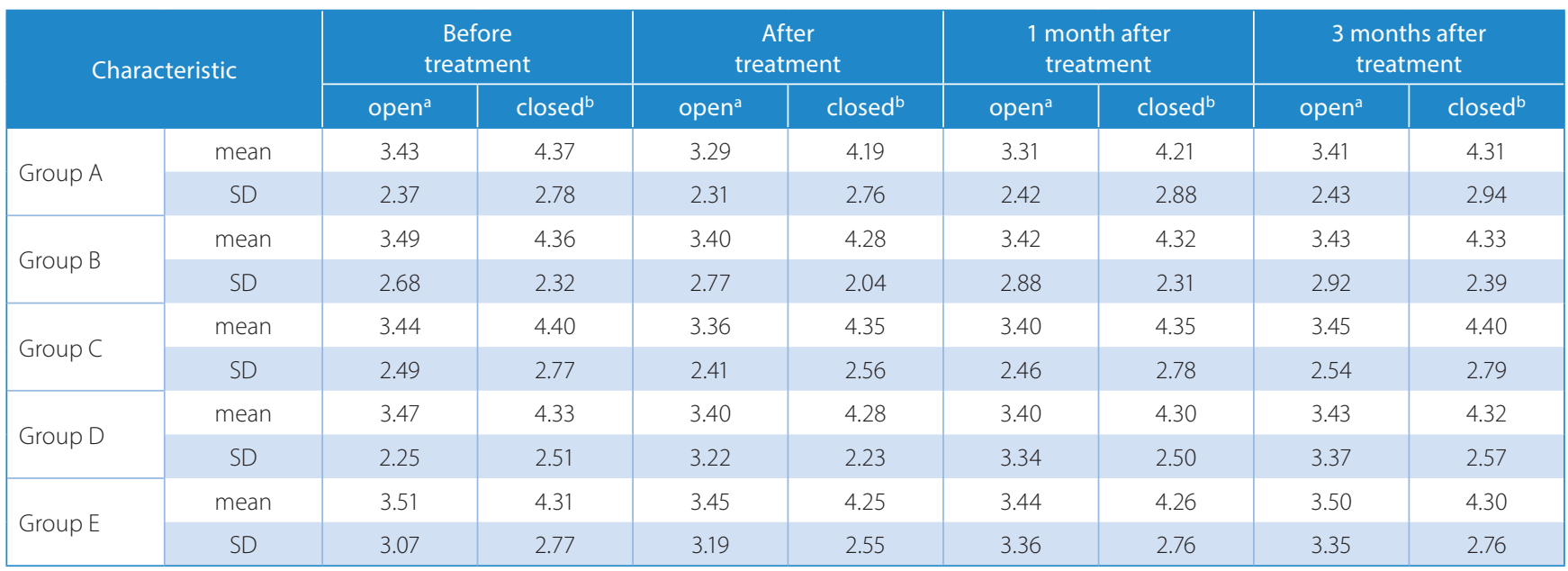

a Friedmann's ANOVA analysis (a total values of significant levels in each groups without the post hoc Bonferroni's test): group A ( $p>0.05$ );

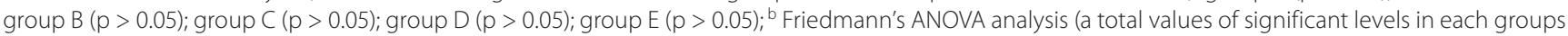
without the post hoc Bonferroni's test): group A ( $p>0.05)$; group B ( $p>0.05)$; group C $(p>0.05)$; group D ( $p>0.05)$; group E $(p>0.05)$.

of studies fail to meet the criteria of the EBM\&P, which makes it extremely difficult to carry out a clear and objective analysis of the clinical efficacy of the treatments that are widely used in everyday practice.

Omar et al. studied the efficacy of magnetic therapy (4 mT, $50 \mathrm{~Hz}, 20 \mathrm{~min}, 5$ treatments/week) in 40 patients presenting with pain in the lumbosacral spine. ${ }^{27}$ The patients were randomly assigned to 2 comparison groups (a group treated with a magnetic field, $\mathrm{n}=20$; and a placebo group with simulated treatments, $\mathrm{n}=20$ ). Before the commencement of the study and after its completion (3 weeks), a measurement was taken of the surface electromyography of selected groups of back muscles, and an assessment was made of the pain symptoms in accordance with the Visual Analogue Scale and the Oswestry questionnaire. A statistically significant reduction in pain was recorded under the influence of the magnetic field compared to the placebo group ( $\mathrm{p}=0.024$ in the VAS and $\mathrm{p}<0.001$ in the Oswestry questionnaire). In the case of the electromyography parameters as well, significantly more beneficial effects were observed in the exposed group $(\mathrm{p}=0.022$ for the parameter of relative latency of the erector spinae muscles). A weakness of the study, however, was a lack of strictly defined inclusion and exclusion criteria and no follow-up analysis.

Thuile and Walzl studied the effects of magnetic field therapy on patients presenting with lumbar radiculopathy and neck pain after sustaining a whiplash-type injury. ${ }^{28}$ The experiment involved 100 patients suffering from low back pain, $92 \%$ of whom had additionally sustained a whiplash injury of the neck section of the spine. Therapeutic progress was evaluated with the Lasègue test in the case of the lower section of the spine, and with the subjective visual analogue pain scale in examining the neck section. After a 2-week therapy, in the group subjected to physical treatments $(8 \mathrm{mT}, 50 \mathrm{~Hz}, 20 \mathrm{~min})$, the Lasègue test was negative in $68 \%$ of patients (as compared to only $36 \%$ before the therapy). In the control group (placebo), no changes in this respect were recorded. With regard to the neck section of the spine, the magnetic field therapy also brought about a positive effect, as the pain symptoms decreased on average by 2.2 points on the VAS. In the control group, this parameter did not improve. Limitations of the study included a lack of objective measurement tools, the heterogeneity of the population and an evaluation of only the early effects of the therapy.

Oke and Umebese used magnetic therapy in 16 patients, randomly assigned to 2 comparison groups. ${ }^{29}$ All patients took oral non-steroidal anti-inflammatory medication, and 8 patients were additionally exposed to magnetic field therapy $(10 \mathrm{mT}, 50 \mathrm{~Hz}, 30 \mathrm{~min})$ for 9 days. After completion of the therapy, a significantly greater improvement was observed in patients subjected to physical treatments. Two serious limitations of the study were its small population and methodological errors - statistical inference based on Student's t-test for 8 cases (in addition, the study does not indicate whether the distributions were normal). Moreover, the application of analgesics was also misguided, as it was difficult to evaluate the analgesic effect of physical therapy or of pharmacotherapy, because they had been combined.

Ratajczak et al. evaluated the influence of laser therapy and magnetotherapy in conjunction with kinesiotherapy used in patients with degenerative lumbosacral spine disease. ${ }^{30}$ The study involved 30 patients aged from 41 to 62 years. The patients were ordered to undergo a series of 10 treatments using laser light, magnetic therapy and kinesiotherapy. All subjects were examined pre- and post-therapy by using the Lasègue test and by measuring pain intensity with the VAS test. Also, the mobility of their lumbosacral spine was measured with a Saunders digital inclinometer (Pearson Surgical, 
Sylmar, USA). An analysis of the mean values of the studied parameters, reflecting the range of spinal mobility, showed higher values in the post-therapy examination. The mobility range was found to have improved in all planes. After the VAS test, a statistically significant difference was observed between the pre- and post-therapy results. Before therapy, the Lasègue sign was positive in $43.4 \%$ of the patients, while after the therapy $20 \%$ of the patients had a positive sign. A methodological error in the above study was the fact that instead of using monotherapy in the comparison groups, the study used a combination of all the physical methods and motor improvement within a single group. Without comparing individual treatments to each other, it is impossible to draw any conclusions on the efficacy of the magnetic field - one may only state that the combination therapy was effective.

On the other hand, Janiszewski conducted a clinical trial involving 53 patients with osteoarthritis of the lower back and found that in the study group (magnetic stimulation $30 \mu \mathrm{T}$, $190 \mathrm{~Hz}, 20 \mathrm{~min}$ ) a significant reduction in pain symptoms occurred and the duration of morning stiffness was shorter. ${ }^{31}$ Patients were administered treatments for a period of 4-6 weeks. The weakness of this study, however, was a lack of objective measurement tools and an evaluation limited only to the early effects.

A study by Pasek et al. analyzed the therapeutic efficacy of magnetic stimulation on various nosological units. ${ }^{32}$ The study was based on gathering information through anonymous questionnaires. In total, 1,874 patients participated in the study and were divided into sub-groups, depending on the diagnosis. The authors proved that after a series of treatments the patients experienced a reduction or clearance of pain symptoms, as well as an increased range of mobility in their joints, spin and paretic extremities. Shortcomings of the study included a significant dispersion of the population and a lack of reliable examination of the participants (assessment through a questionnaire).

In another study, Pasek et al. studied the influence of a treatment using a magnetic field and polarized light on back pain syndromes, and on sciatic neuralgia in particular. ${ }^{33}$ The study involved a group of 47 patients, 30 women and 17 men, diagnosed with sciatic neuralgia caused by degenerative intervertebral disc disease. The diagnosis was confirmed with a preliminary medical examination, a radiological examination and a CT scan of the lumbar spine. The patients were divided into 3 study groups. The $1^{\text {st }}$ group was treated with magnetic therapy with the following parameters: a frequency of $40 \mathrm{~Hz}$, magnetic induction of $10 \mathrm{mT}$ with a triangular magnetic field, and a duration of $12 \mathrm{~min}$. The $2^{\text {nd }}$ group was subjected to magnetic stimulation with the Viofor JPS apparatus (Med \& Life, Komorów, Poland) using the M2P2 program, field intensity of 8 , and treatment duration of $12 \mathrm{~min}$. The $3^{\text {rd }}$ group was treated with magnetoledotherapy, also using the Viofor JPS apparatus, M2P2 program and optical IR radiation (wavelength $830 \mathrm{~mm}$ ) with a treatment duration of $12 \mathrm{~min}$. Each patient underwent the Lasègue test both before and after the therapy, and was examined with the subjective assessment of experienced pain using VAS. In addition, a questionnaire was used to assess the frequency of taking analgesic medication and quality of life was evaluated using the EuroQoL scale. The authors demonstrated that in each of the study groups the treatment resulted in a significant reduction of pain, a reduced demand for analgesic medication, and improved quality of life. The study did not state a significant advantage of any of the analyzed methods in relation to the results obtained. Unfortunately, the study did not incorporate any verification of therapeutic effects based on objective measurement tools.

Nowadays, application of magnetic stimulation is widely used, not only in the therapy of persons suffering from pain in the motor system, but also in stomatology, neurology, and in the treatment of internal organ dysfunction.

In the period of 2003-2004, Kapłun et al. at the rehabilitation ward in Hrubieszów (Poland) attempted to evaluate the usefulness of magnetic stimulation treatments in patients after a stroke with low back discopathy as a concomitant disease. ${ }^{34}$ The rehabilitation program covered 318 patients, but the analysis was carried out with respect to 53 patients after brain stroke of different etiology, which included 17 women (32\%) and 36 men (68\%). Electromagnetic therapy using the Viofor JPS apparatus (Med \& Life, Komorów, Poland) was recommended in order to reduce spasticity, normalize the emotional sphere, normalize the functions of the circulatory system, and obtain an analgesic effect. These treatments were an addition to pharmacological therapy and kinesiotherapy. The patients received treatments twice a day for $12 \mathrm{~min}$ using the M2P2 program, for 5 days/week, i.e., about 20-30 treatments were administered. The effects of the therapy were assessed through a general medical examination, evaluation of the functional status using the Brunnström scale and evaluation of muscle tension using the Ashworth scale. The results were compared with a group of patients treated without the application of a magnetic field. Irrespective of the etiology of the stroke, the time elapsed from the onset of the disease and the concomitant diseases, in the study group a significant improvement was obtained in 28 patients (52.8\%), an improvement in 20 patients (37.8\%), a lack of improvement in 3 patients (5.7\%), and a deterioration in 2 patients (3.7\%). The therapeutic effects concerned functional ability and spastic reaction. The study did, however, lack an analysis of the long-term results and a unification of the rehabilitation program for all the patients studied. Another weakness was the incorporation of pharmacotherapy, which additionally impeded verification of the obtained results and made it more difficult to draw unequivocal conclusions.

One can see from the above and from the review of literature presented in the introduction, there is a shortage of well-planned, methodologically impeccable, randomized clinical studies regarding the discussed subject. 
It is not possible to refer the results obtained in our study to any data in the available literature, as this was the first such clinical trial among publications worldwide.

Despite the innovative character of this study and its novel elements, it also contains a number of limitations. It would certainly be worthwhile to supplement the project in the future with other modern and objective measurement tools, such as muscle electromyography or systems for movement and balance analysis.

Unfortunately, balance measurements taken with the use of stabilometric platforms are characterized by a certain lability and a relatively low (despite their immense referentiality in biomedical sciences) measurement repeatability (even though all measurements were performed by the same person in compliance with the principles of metrology, and therefore the substantial standard deviations in the obtained parameters attest to the fallibility of the device, which impacts the behavior of statistical tests during analysis, as well as the inference process itself). Another shortcoming of the study was the fact that the research was carried out at a single facility, which significantly extended the time of the project (nearly 3 years) and affected the final number of patients. A multi-facility project would have allowed access to a greater number of patients and a better selection, and would have substantially shortened the project duration. It may also be worthwhile to continue the work and gather greater populations in individual groups, in order to verify the obtained results using statistical parametric tests. A weakness of this study was also the relatively high measurement error during the observation of mobility of the hip joint and the lumbar region of the spine. When designing the study, we tried to reduce this deviation by making sure that all the measurements were made by the same person (a mean of 5 trials). However, the listed shortcomings certainly constituted significant limitations of the actions undertaken in this project. It must also be mentioned that the long-term follow-up observation (at 1 month and 3 months post-therapy) was extremely difficult and subject to certain limitations. During the trial, at different stages, (after qualification for treatment to a given group) 16 participants were successively excluded from the study. It is worth noting that as many as 14 people from this subpopulation were not able to comply with the requirement to discontinue analgesics for such a long period of time. The other 2 cases were a viral infection, which prevented the patient from systematic participation in treatments, and the sudden, unplanned departure of another patient, which also resulted in exclusion from the project. The abovementioned circumstances affected the final number of participants in the comparison groups.

In conclusion, further randomized clinical research trials regarding the application of magnetic fields in various areas should certainly be continued, in order to verify the findings of this study. No doubt, studies conducted by other institutions would enable the comparison of experience gained and a broadening of the knowledge on the subject.

\section{Conclusions}

Magnetic fields studied in the present clinical trial, in combination with specialist motor rehabilitation ( 5 times a week for 3 weeks), may be efficient in reducing certain symptoms of spinal discopathy at L5-S1, but the resulting remission is only acute and short-term (without further continuation of kinesiotherapy). The study has shown that application of magnetic therapy $(10 \mathrm{mT}, 50 \mathrm{~Hz}$, $20 \mathrm{~min}$ ) significantly reduces pain symptoms and leads to an improvement of functional ability in patients with low back pain, based on the analysis of both subjective and objective parameters. However, the application of magnetic therapy with an induction value of $5 \mathrm{mT}$ and of magnetic stimulation appears to be ineffective and pointless in the treatment of lumbosacral discopathy (within the scope studied in this paper).

\section{References}

1. Krismer M, van Tulder M.; Low Back Pain Group of the Bone and Joint Health Strategies for Europe Project. Strategies for prevention and management of musculoskeletal conditions: Low back pain (nonspecific). Best Pract Res Clin Rheumatol. 2007;21:77-91.

2. Calvo-Muñoz I, Gómez-Conesa A, Sánchez-Meca J. Prevalence of low back pain in children and adolescents: A meta-analysis. BMC Pediatr. 2013;13:14.

3. Borenstein DG. Epidemiology, etiology, diagnostic evaluation, and treatment of low back pain. Curr Opin Rheumatol. 2001;13:128-134.

4. Hoy D, Bain C, Williams $G$, et al. A systematic review of the global prevalence of low back pain. Arthritis Rheum. 2012;64:2028-2037.

5. Meucci RD, Fassa AG, Faria NMX. Prevalence of chronic low back pain: Systematic review. Rev Saúde Pública. 2015;49:1. doi:10.1590/S00348910.2015049005874

6. Zhang Y, Guo T, Guo X, Wu S. Clinical diagnosis for discogenic low back pain. Int J Biol Sci. 2009;5:647-658.

7. Garg A, Gerr F, Katz JN, Marras WS, Silverstein B. Low back pain and the workplace. JAMA. 2007;298:403-404.

8. Morton M. Spinal pain syndromes. Przew Lek. 2008;5:45-55.

9. Elder BD, Witham TF. Low back pain and spondylosis. Semin Neurol. 2016;36:456-461.

10. Allegri M, Montella S, Salici F, et al. Mechanisms of low back pain: A guide for diagnosis and therapy. F1000 Research. 2016;5. doi:10. 12688/f1000research.8105

11. Hoozemans MJM, Koppes LLJ, Twisk JWR, van Dieën JH. Lumbar bone mass predicts low back pain in males. Spine. 2012;37:1579-1585.

12. Golob AL, Wipf JE. Low back pain. Med Clin North Am. 2014;98: 405-428.

13. Goubert D, Oosterwijck JV, Meeus M, Danneels L. Structural changes of lumbar muscles in non-specific low back pain: A systematic review. Pain Physician. 2016;19:985-1000.

14. Furlan AD, Pennick V, Bombardier C, van Tulder M; Editorial Board, Cochrane Back Review Group. 2009 updated method guidelines for systematic reviews in the Cochrane Back Review Group. Spine. 2009;34:1929-1941.

15. Furlan AD, Yazdi F, Tsertsvadze A, et al. A systematic review and meta-analysis of efficacy, cost-effectiveness, and safety of selected complementary and alternative medicine for neck and low-back pain. Evid-Based Complement Altern Med ECAM. 2012;953139. doi: 10.1155/2012/953139

16. Chou R, Huffman LH; American Pain Society, American College of Physicians. Nonpharmacologic therapies for acute and chronic low back pain: A review of the evidence for an American Pain Society/American College of Physicians clinical practice guideline. Ann Intern Med. 2007;147:492-504.

17. Koes BW, van Tulder MW, Thomas S. Diagnosis and treatment of low back pain. BMJ. 2006;332:1430-1434. 
18. Kuryliszyn-Moskal A. Management of low back pain: Treatment strategies. Rheumatology. 2009;47(6):368-371.

19. Rubinstein SM, van Middelkoop M, Kuijpers T, et al. A systematic review on the effectiveness of complementary and alternative medicine for chronic non-specific low-back pain. Eur Spine J. 2010;19: 1213-1228.

20. Delitto A, George SZ, Van Dillen LR, et al.; Orthopaedic Section of the American Physical Therapy Association. Low back pain. J Orthop Sports Phys Ther. 2012;42(4):A1-A57.

21. McCaskey MA, Schuster-Amft C, Wirth B, Suica Z, de Bruin ED. Effects of proprioceptive exercises on pain and function in chronic neckand low back pain rehabilitation: A systematic literature review. BMC Musculoskelet Disord. 2014;15:382.

22. Standaert CJ, Friedly J, Erwin MW, et al. Comparative effectiveness of exercise, acupuncture, and spinal manipulation for low back pain. Spine. 2011;36:120-130.

23. Bouche K, Stevens V, Cambier D, Caemaert J, Danneels L. Comparison of postural control in unilateral stance between healthy controls and lumbar discectomy patients with and without pain. Eur Spine J. 2006;15:423-432.

24. Salavati M, Mazaheri M, Negahban $H$, et al. Effect of dual-tasking on postural control in subjects with nonspecific low back pain. Spine. 2009;34:1415-1121.

25. Mazaheri M, Coenen P, Parnianpour M, Kiers H, van Dieën JH. Low back pain and postural sway during quiet standing with and without sensory manipulation: A systematic review. Gait Posture. 2013;37:12-22.

26. Ruhe A, Fejer R, Walker B. Center of pressure excursion as a measure of balance performance in patients with non-specific low back pain compared to healthy controls: A systematic review of the literature. Eur Spine J. 2011;20:358-368.

27. Omar AS, Awadalla MA, El-Latif MA. Evaluation of pulsed electromagnetic field therapy in the management of patients with discogenic lumbar radiculopathy. Int J Rheum Dis. 2012;15:101-108.

28. Thuile C, Walzl M. Evaluation of electromagnetic fields in the treatment of pain in patients with lumbar radiculopathy or the whiplash syndrome. NeuroRehabilitation. 2002;17:63-67.

29. Oke KI, Umebese PFA. Evaluation of the efficacy of pulsed electromagnetic therapy in the treatment of back pain: A randomized controlled trial in a tertiary hospital in Nigeria. West Indian Med J. 2013;62: 205-209.

30. Ratajczak B, Ryfa R, Boerner E, Kuciel-Lewandowska J, Hawrylak A, Demidaś $A$. Assessment the influence of the lasertherapy and magnetotherapy in connection with kinesitherapy used by patients with the degenerative low back disease. Adv Rehabil. 2013;25:13-18.

31. Janiszewski M. Wpływ terapeutycznego systemu magnetostymulacyjnego (MRS 2000) na niektóre wskaźniki biomechaniczne narządu ruchu u pacjentów z chorobą zwyrodnieniową stawów. Acta Bio-Opt InfMed. 1998;4:73-75.

32. Pasek J, Pasek T, Sieron A. Some practical recommendations on the use of magnetic fields and light in physical medicine. Acta Bio-Opt Inform Medica. 2007;13:284-285.

33. Pasek J, Kwiatek P, Pasek T, Szajkowski S, Szewc A, Sieroń A. Application of magnetic field and visible light in the treatment of low back pain and sciatic neuralgia. Curr Neurol. 2012;12:65-68.

34. Kapłun E, Kapłun D, Majcher P, Fatyga M. Evaluation of magnetstimulation usefulness using VIOFOR JPS in rehabilitation of patients after stroke. Adv Rehabil. 2004;18. 